\title{
QUÍMICA MINERAL DAS ROCHAS VULCÂNICAS E LAMPRÓFIROS ESPESSARTÍTICOS DA ASSOCIAÇÃO SHOSHONÍTICA DE LAVRAS DO SUL-RS
}

\author{
EVANDRO FERNANDES DE LIMA* \& LAURO VALENTIM STOLL NARDI*
}

\begin{abstract}
MINERAL CHEMISTRY OF VOLCANIC ROCKS AND LAMPROPHYRES OF LAVRAS DO SUL SHOSHONITIC ASSOCIATION, SOUTHERNMOST BRAZIL The Lavras do Sul Shoshonitic Association, situated in the southernmost Brazil, is composed of basic to acid volcanic and plutonic rocks, related to the late stages of Brasiliano Cycle. Spessartitic lamprophyres are associated to the late stages of shoshonitic magmatism. Major and some trace elements ( $\mathrm{Ba}, \mathrm{Sr}, \mathrm{Ni}, \mathrm{Cr}, \mathrm{Ti})$, were obtained by microprobe determinations, in major mineral phases of basic to intermediate volcanic rocks and lamprophyres of Lavras do Sul Shoshonitic Association. The composition of plagioclases is sodium enriched in relation to calc-alkaline rocks, varying from labradorite to andesine. The relatively low An-content is ascribed mainly to the alkali-calcic character of shoshonitic magmatism. The presence of albite in the lamprophyres is a result of late hydrothermal activity. The relatively high $\mathrm{Ba}$ content of plagioclases suggest that the mineral/liquid partition coefficient for this element in shoshonitic liquids is close to 1 . Olivine $\left(\mathrm{Fo}_{67}\right)$, with relatively low $\mathrm{Mg} / \mathrm{Fe}$ ratios, and clinopyroxene, with composition close to diopside, are the main ferromagnesian phases, whose compositions are typical of basic and intermediate shoshonitic rocks. Magnesiohastingsite is the amphibole present in the lamprophyres, associated with clinopyroxene relicts which are diopside enriched relative to those oberved in trachybasalts. The coherence between mineral phases and whole-rock chemical compositions is consistem with differentiation processes dominated by fractional crystallisation, except for the lamprophyric liquids, whose evolution may have involved the assimilation of crustal components.
\end{abstract}

Keywords: Shoshonites, mineral chemistry, lamprophyres, Sul-rio-grandense Shield

RESUMO A Associação Shoshonítica de Lavras do Sul, situada no extremo sul do Brasil é constituída por rochas vulcânicas básicas até ácidas e rochas plutônicas relacionadas ao final do Ciclo Brasiliano. Lamprófiros espessartíticos são as manifestações mais tardias desde magmatismo shoshonítico. Neste trabalho são apresentados os resultados de elementos maiores e alguns elementos-traço ( $\mathrm{Ba}, \mathrm{Sr}, \mathrm{Ni}, \mathrm{Cr}$, Ti), obtidos por microssonda eletrônica, nas principais fases minerais das rochas vulcânicas básicas, intermediárias e lamprófiros da Associação Shoshonítica de Lavras do Sul. A composição do plagioclásio é mais sódica do que as normalmente observadas nas rochas cálcico-alcalinas, variando de labradorita a andesina. O cárater álcali-cálcico possivelmente deternina este enriquecimento no componente albita. Os conteúdos elevados de $\mathrm{Ba}$ dos plagioclásios indicam um coeficiente de partição mineral/líquido em torno da unidade. A olivina $\left(\mathrm{Fo}_{67}\right)$, com razões $\mathrm{Mg} / \mathrm{Fe}$ relativamente baixas e clinopiroxênio com composição próxima do diopsído, representam as principais fases ferromagnesianas, sendo estas típicas das rochas shoshoníticas básicas a intermediárias. Magnesiohastingsita é o anfibólio nos lamprófiros, além de relíctos de clinopiroxênio cuja composição aproxima-se daquelas observadas nos traquibasaltos. A combinação dos dados de química mineral com os resultados litoquímicos é coerente com a hipótese de cristalizacão fracionada como o processo dominante de diferenciação magmática dos termos básicos para intermediários. No caso dos líquidos lamprofíricos admite-se envolvimento de assimilação crustal.

Palavras-chave: Shoshonitos, química mineral, lamprófiro, Escudo Sul-rio-grandense.

INTRODUCÃ̃O A região de Lavras do Sul situa-se na porção sudoeste do Escudo Sul-rio-grandense, distando 310 $\mathrm{Km}$ de Porto Alegre. Nesta área afloram rochas efusivas básicas a intermediárias, depósitos piroclásticos, corpos hipabissais monzoníticos a riolíticos e lamprófiros espessartíticos, além de rochas monzograníticas a granodioríticas reunidos por Nardi \& Lima (1985) na Associação Shoshonítica de Lavras do Sul -ASLS- (Fig. 1). Este grupo de rochas sucede as rochas cálcico-alcalinas brasilianas, representadas por metagranitóides e antecede o magmatismo alcalino supersaturado pós-orogênico. A área estudada tem como limites os paralelos $-30^{\circ} 42^{\prime} 47^{\prime \prime}$ e $-31^{\circ} 00^{\prime}$ e os meridianos $53^{\circ} 45^{\prime}$ e $54^{\circ} 00$, que definem geograficamente, uma estreita faixa no extremo sul da Folha de Arroio América (SH.22-YA-IV1/MI2995/1) e a Folha de Lavras do Sul (SH-22-Y-A-IV-3/ MI 2995/3) confeccionadas na escala $1: 50.000$, pelo Ministério do Exército- Diretoria de Serviço Geográfico em 1976. Os principais aspectos de química mineral e litoquímica diagnosticados nas rochas da ASLS, indicam que os termos básicos em geral microporfiríticos, e a presença de olivina $\left(\mathrm{Fo}_{67}\right)$, augita, labradorita e ilmenita, que cristalizaram a partir de um magma com características evoluídas (baixos teores $\mathrm{Co}$, $\mathrm{Ni}$ e $\mathrm{Cr}$ e mg 0,7). As caraterísticas geoquímicas dos traquibasaltos, como o baixo $\mathrm{TiO}_{2}$, o caráter saturado em $\mathrm{SiÜ2}$, o conteúdo relativamente elevado de $\mathrm{Al}_{2} \mathrm{O}_{3}, \mathrm{Rb}, \mathrm{Ba}, \mathrm{Sr}$ e ETRL aliadas a uma razão $\mathrm{K}_{2} \mathrm{O} / \mathrm{Na}_{2} \mathrm{O}$ em torno da unidade e a conteúdos moderados de HFSE, determinam a afinidade Shoshonítica destas rochas e o seu relacionamento com zonas orogênicas.
As rochas vulcânicas intermediárias são volumetricamente mais expressivas e são constituídas por fenocristais de andesina-labradorita, com hábitos distintos, decorrentes de fenómenos de descompressão, associados a pequenas percentagens de augita, olivina e titanomagnetita. Possuem uma grande percentagem de matriz com natureza hemicristalina. $\mathrm{O}$ estudo de cinco depósitos efusivos indica que estes foram gerados a partir da cristalização fracionada de olivina + clinopiroxênio de líquidos traquibasálticos (Lima 1995, Lima \& Nardi 1998). Este mecanismo evolutivo é responsável pelos padrões geoquímicos das rochas traquiandesíticas da ASLS, que comparativamente aos dos termos básicos diferenciam-se pelo crescimento acentuado de elementos incompatíveis, tais como $\mathrm{Ba}, \mathrm{Sr}$, $\mathrm{Rb}$ e álcalis, em especial, $\mathrm{K}_{2} \mathrm{O}$, bem como pelo aumento nos conteúdos de ETR e $\mathrm{Al}_{2} \mathrm{O}_{3}$, os quais caracterizam geoquimicamente as rochas vulcânicas intermediárias. Xenocristais de plagioclásio identificados tanto nas rochas vulcânicas básicas como nas intermediárias são resultantes da assimilação de rochas encaixantes, que, no entanto, não mascara os padrões geoquímicos decorrentes da cristalização fracionada. A evolução das rochas vulcânicas intermediárias envolveu além das fases máficas identificadas, o expressivo fracionamento de plagioclásio, responsável pela formação de corpos cumuláticos leucodioríticos aflorantes a nordeste do Complexo Granítico de Lavras (Nardi 1984). O fracionamento de fases anidras persistiu até o magmatismo atingir o campo das composições monzoníticas ou latíticas.

Os lamprófiros espessartíticos relacionam-se aos estágios finais do magmatismo shoshonítico, destacando-se petro- 
graficamente a textura panidiomórfica (Lima \& Nardi 1991). Mi-neralogicamente são constituídos por anfibólio do tipo magnesiohastingsita, associado a relictos de clinopiroxênios, cujas composições são enriquecidas em componente diopsídio com relação aos das rochas básicas da ASLS. Os padrões geoquímicos as semelham-se, em parte, aos das rochas traquiandesíticas, porém apresentam conteúdos mais elevados de álcalis, $\mathrm{MgO}$, Ni e $\mathrm{Cr}$ e mais baixos de $\mathrm{Al}_{2} \mathrm{O}_{3}, \mathrm{Sr}, \mathrm{Zr}$ e Nb . Ao contrário dos demais segmentos da ASLS, podem ter sido gerados pela modificação de um líquido básico shoshonítico por mecanismos de assimilação de crosta continental.

Os dados isotópicos para sistemática $\mathrm{Rb}-\mathrm{Sr}$, em rochas vulcânicas e hipabissais da ASLS, indiçam idades da ordem de $653 \pm 23$ Ma e razões iniciais $\mathrm{Sr}^{87} / \mathrm{Sr}^{86}$ em torno de 0,704 . Dados isotópicos de $\mathrm{U}$ e $\mathrm{Pb}$ em zircão indicam idades de $592 \pm 7$ Ma para os granitóides shoshoníticos do núcleo deste Complexo (Remus et al. 1997), assinalando provavelmente os estágios finais deste magmatismo.

O presente trabalho caracteriza quimicamente as fases minerais das rochas vulcânicas da Associação Shoshonítica de Lavras do Sul (ASLS). Inicialmente abordou-se de forma isolada os dados referentes aos feldspatos dos diferentes tipos de rocha, tendo-se em conta a essencialidade desta fase, mesmo nas rochas lamprofiricas. Em seguida, foram caracterizadas as principais fases máficas, destacando-se as diferenças, quando presentes, na sua composição química, de um tipo de rocha para outro. Aspectos texturais e a comparação com fases minerais de outras associações shoshoníticas são também discutidos.

MÉTODOS DE TRABALHO Os dados de química mineral foram obtidos por microssonda nas seguintes ins-tituições: -Université de Nancy I, Laboratoire de Chimie Minérale: microssonda CAMECA -SX 50; Laboratoire du Muséum National de Histoire Naturelle de Paris: microssonda CAMEB AX; Université Pière et Marie Curie, Paris VI, Laboratoire de Petrologie Mineralogique: microssonda CAMEBAX e microssonda CAMECA - SX 50. Nas análises com microssonda eletrônica foram utilizadas as seguintes condições instrumentais: potencial de aceleração $15 \mathrm{kV}$, tempo de integração de contagens 8 ou $10 \mathrm{~s}$ e correção ZAF.

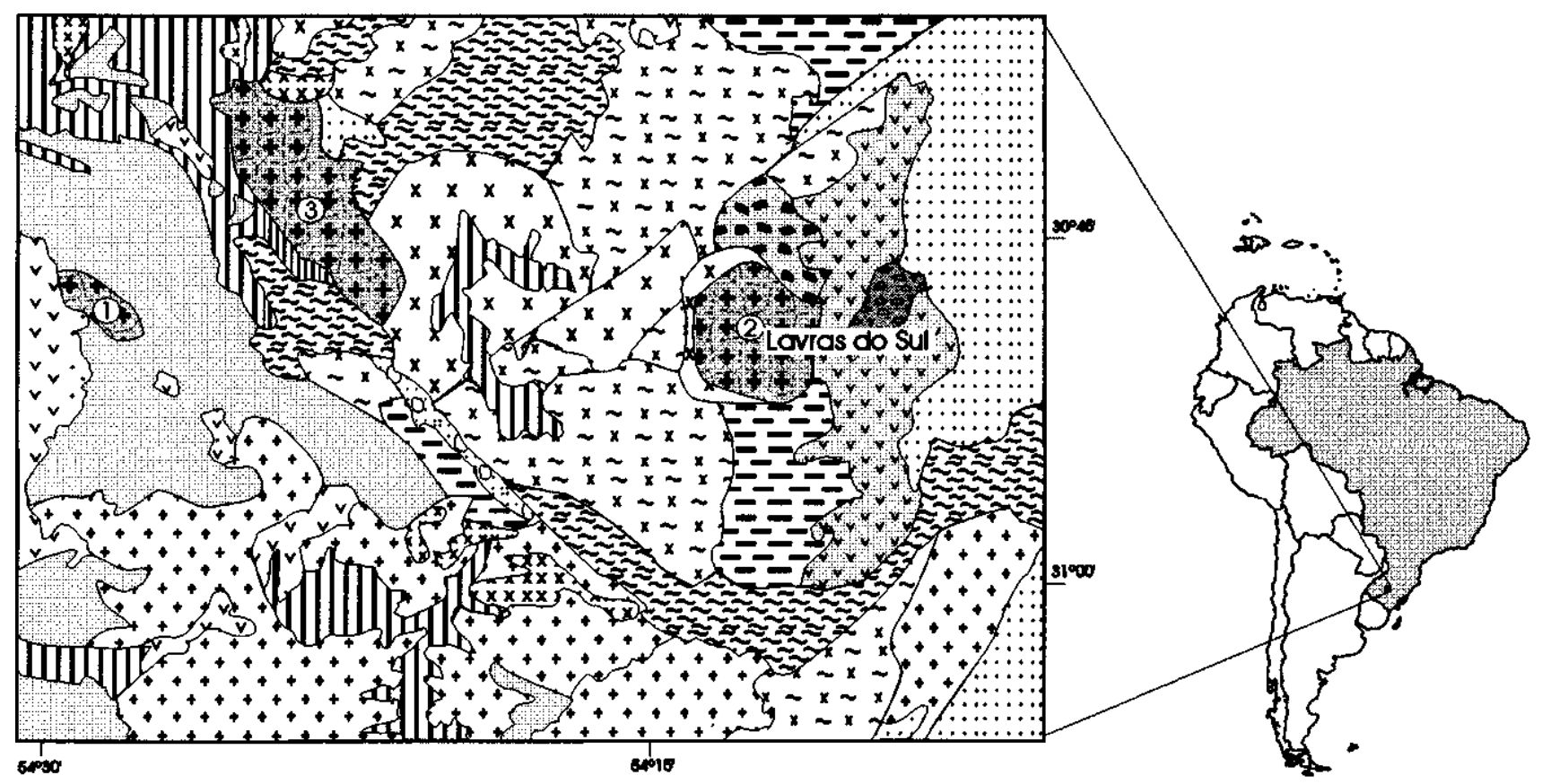

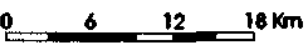

III Seqüências de cobertura gonduânicas

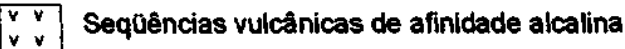

$\left.\begin{array}{|ll}x & x \\ X & X\end{array}\right]$ Suite intrusiva saibro

++
++

::: Sequências de cobertura Eo-paleozóicas

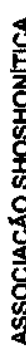

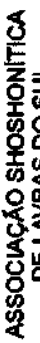
38

Conglomerados vulcánicos

Monzonitos a quartzo-monzonitos

$\Delta$

Granitos Núcleo do Complexo Granitico Lavras (1) Complexo Granitico Santa Rita

Traqui-basaltos e traqui-andesitos

e plroclásticas associadas

Seqüência sedimentar

$\bar{x}$ Complexos gnáissicos e metagraníticos

Seqüüncias metavulcânicas e metassedimentares

Complexo granulitico Santa Maria Chico

Figura l-Mapa geológico da região de Lavras do Sul. Figure 1 - Geologic map of Lavras do Sul region. 
No cálculo das fórmulas estruturais dos minerais silicatados utilizou-se o programa MINFILE (versão 5.0) de Afifi \& Essene (1988).

\section{FELDSPATOS DAS ROCHAS VULCÂNICAS DA} ASLS Os feldspatos representam a fase mineral dominante em todas as rochas da ASLS, inclusive nos lamprófiros, onde ocorrem quase que exclusivamente na matriz. Os dados sobre a composição química dos plagioclásios e dos feldspatos potássicos são abordados, inicialmente, para cada grupo de rocha, com o objetivo de facilitar a correlação com os dados petrográficos apresentados.

\section{Feldspatos das Rochas Vulcânicas Básicas Nas}

rochas básicas, o plagioclásio, cujas análises químicas por microssonda eletrônica são apresentadas na tabela 1 , está representado por 3 populações distintas:

i) fenocristais tabulares subédricos a euédricos, maclados;

ii) fenocristais subédricos arredondados, zonados, com macias

incipientes ou ausentes;

iii) feldspatos (micrólitos) da matriz.

No primeiro grupo observa-se a presença de labradorita sódica, com variações de Ansi-58, que se enquadra na moda estatística definida por Ewart (1982) para composições de fenocristais de plagioclásios em basaltos orogênicos alto potássio a traquibasaltos. Gill (1981) destaca que o conteúdo de An em plagioclásios dos primeiros, em geral, é inferior ao dos fenocristais de associações cálcico-alcalinas típicas. $\mathrm{O}$ teor mais baixo de anortita, para composições basálticas shoshoníticas, segundo Pe-Piper (1984), pode estar relacionado ao conteúdo de $\mathrm{K}_{2} \mathrm{O}$ do magma, o que é coerente com o caráter álcali-cálcico das rochas desta série. Esta autora, examinando composições básicas, baixo e alto potássio, observou que nestas últimas, é comum a cristalização de labradorita sódica acompanhada de clinopiroxênio cálcico $\left(\mathrm{Al}_{2} \mathrm{O}_{3}\right.$ $3 \%$ ), enquanto nas primeiras predominam bytownita e clinopiroxênio cálcico, menos aluminoso.

Os cristais tabulares possuem teores entre 3-5\% da molécula de ortoclásio (Or), que coincidem com os valores encontrados em fenocristais de plagioclásios de rochas básicas de outras associações shoshoníticas (Mackenzie 1976; Villari \& Nathan 1978). São também observadas neste primeiro grupo, discretas zonações do tipo oscilatória normal, caracterizadas por variações decrescentes nos teores de anortita em direção às bordas dos grãos. Possuem um conteúdo de $\mathrm{FeO}^{\text {total }}$ entre 0,51 e $0,86 \%$, que é compatível com os valores observados por Smith (1974) em labradoritas de rochas vulcânicas básicas. Os teores de $\mathrm{MgO}$ são baixos (inferiores a 0,13\%), e possuem uma correlação simpatética com o FeO*.

Os plagioclásios da segunda população se distinguem quimicamente da anterior pelo conteúdo mais baixo de anortita, que os classifica como do tipo andesina (An 35-46), bem como pelo menor conteúdo da molécula de ortoclásio, que atinge um valor máximo de $1,5 \%$. Possuem uma forte zonação oscilatória normal, característica de fenocristais de rochas vulcânicas orogênicas. Tais modificações rítmicas podem estar relacionadas à variações na pressão total ou na atividade de $\mathrm{H}_{2} \mathrm{O}$ na câmara magmática, bem como à difusão dos elementos, que é controlada pelos gradientes composicionais na superficie líquido-cristal (Lofgren 1914 Haase et al. 1980). O hábito subarredondado característico desta população sugere a atuação de processos de reabsorção, desencadeados por mudanças nas condições físicas da câmara magmática, conforme demonstrado por Nelson \& Montana (1992). As análises das diferentes populações são apresentadas no triângulo Ab-An-Or (Fig. 2). A composição mais sódica e a forte zonação composicional dos cristais da segunda população sugere que estes sucedem temporalmente os fenocristais tabulares.

Os conteúdos de $\mathrm{Ba}$ e $\mathrm{Sr}$ nos plagioclásios são elevados. Observa-se, no entanto, fortes variações em um mesmo grão. Ambos os elementos, na maior parte dos casos, têm teores acima de 1000 ppm, atingindo no caso do Sr, valores de até $1,6 \%$.

Feldspatos das Rochas Vulcânicas Intermediárias Os feldspatos das rochas vulcânicas intermediárias (Tab. 2), como os das rochas básicas, podem ser separados em diferentes populações :

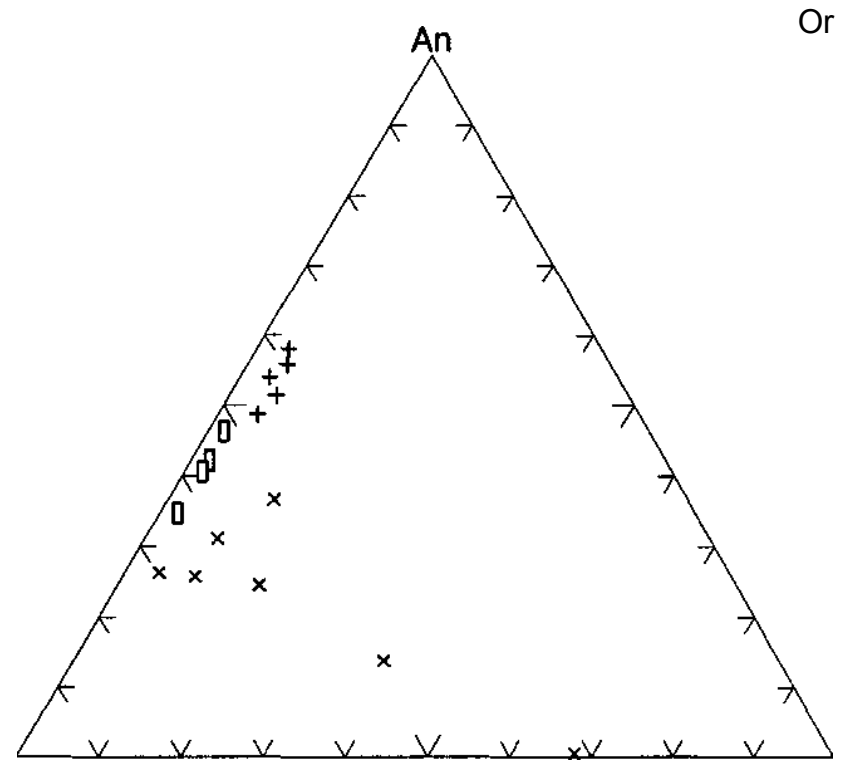

$\mathrm{Ab}$

Figura 2 - Sistema Ab(albita)- An(anortita)- Or(ortoclásio) ilustrando o posicionamento dos fenocristais tabulares (+), fenocristais subédricos arredondados $(\square)$ e grãos da matriz das rochas básicas da ASLS (x).

Figure 2 - Tabular phenocryst (+), rounded subhedral phenocrysts $(\square)$ and groundmassfeldspargrains (x) ofbasic rocksfrom Lavras do Sul Shoshonitic Association in the system Ab-An-Or.

i) fenocristais de plagioclásio, tabulares, subédricos a euédricos com macias polissintéticas bem desenvolvidas; ii) fenocristais de plagioclásio fortemente zonados, alongados, anédricos, com contornos irregulares e textura em peneira. Os grãos contêm internamente e nas bordas material da matriz;

iii) raros fenocristais arredondados, com extinção ondulante e fraturas dendríticas internas, e

iv) micrólitos/cristálitos da matriz.

$\mathrm{O}$ primeiro grupo se caracteriza por teores de $\mathrm{An}_{47-57}$, sendo predominante a composição de $\mathrm{An}_{52}$. A população de fenocristais anédricos possui um teor médio de An4g, mas em alguns casos, compatível com labradorita sódica.

A presença de populações distintas de fenocristais de plagioclásio, como constatado no presente trabalho, seja do ponto de vista químico ou textural, é bastante frequente em rochas andesíticas orogênicas (Gill 1981), enquanto a presença de fenocristais irregulares, com textura em peneira e fortemente zonados envolvem diferentes interpretações, em geral relacionadas a fenómenos de desequilíbrio. $\mathrm{O}$ confronto entre os dados químicos dos diversos tipos de fenocristais de feldspato das rochas vulcânicas intermediárias da ASLS com as diferentes hipóteses de origem permite tecer as seguintes considerações: 
Tabela 1-Composição química e fórmula estrutural (32 oxigênios) dos feldspatos dos traquibasaltos da ASLS. $\mathrm{Tb}=$ fenocristal tabular, $F \mathrm{~s}=$ fenocrístalsubarredondado; $\mathrm{m}$ matriz, $c=$ centro de cristal; $b=$ borda de cristal. Table 1 - Chemical composition and structural formula (32 oxygens) of feldspars from basic rocks of LSSA. Tb $=$ tabular phenocryst, Fs $=$ rounded phenocryst, $m=$ matrix, $c=$ crystal core, $b=$ crystal border.

\begin{tabular}{|c|c|c|c|c|c|c|c|}
\hline & $\begin{array}{l}\text { TBA12 } \\
\text { Tb-c }\end{array}$ & $\begin{array}{l}\text { TBA12 } \\
\text { Tb-b }\end{array}$ & $\begin{array}{l}\text { TBA07 } \\
\text { Fs }\end{array}$ & $\begin{array}{l}\text { TBA07 } \\
\text { Fs }\end{array}$ & $\begin{array}{l}\text { TBA07 } \\
\text { Fs-b }\end{array}$ & $\begin{array}{l}\text { TBA07 } \\
\mathrm{m}\end{array}$ & $\begin{array}{l}\text { TBA07 } \\
\mathrm{m}\end{array}$ \\
\hline $\mathrm{SiO}_{2}$ & 53,40 & 54,55 & 59,05 & 60,74 & 56,84 & 60,71 & 58,69 \\
\hline $\mathrm{TiO}_{2}$ & - & - & 0,03 & 0,12 & - & 0,36 & 0,04 \\
\hline $\mathrm{Al}_{2} \mathrm{O}_{3}$ & 28,66 & 28,22 & 25,43 & 24,13 & 26,84 & 22.94 & 25,50 \\
\hline $\mathrm{FeO}$ & 0.60 & 0.86 & - & 0,21 & 0.25 & 0,36 & 0,43 \\
\hline $\mathrm{MnO}$ & $=$ & - & - & * & 0,05 & 0,06 & 0,11 \\
\hline $\mathrm{MgO}$ & 0,12 & 0,09 & - & - & - & 0,03 & 0.02 \\
\hline $\mathrm{CaO}$ & 11,88 & {$[1,29$} & 7,34 & 5,56 & 8.56 & 5,65 & 5,15 \\
\hline $\mathrm{Na}_{2} \mathrm{O}$ & 4,28 & 4,46 & 7,26 & 6,71 & 6,24 & 8,18 & 7,23 \\
\hline $\mathrm{K}^{2} \mathrm{O}$ & 0,58 & 0,72 & 0,24 & - & 0,23 & 0,55 & 1,28 \\
\hline TOTAL & 100 & 102,7 & 99,60 & 98,03 & 99,32 & 98,67 & 99,04 \\
\hline $\mathrm{Ba}$ & 4700 & .4900 & 200 & 300 & - & - & - \\
\hline $\mathrm{Sr}$ & 900 & 20400 & 2300 & 1800 & 3100 & 1900 & 1900 \\
\hline $\mathrm{Si}$ & 9,730 & 9,801 & 10,598 & 10,963 & 10,283 & 10,990 & 10,613 \\
\hline Al & 6,154 & 5,977 & 5,379 & 5,133 & 5,723 & 4,894 & 5,434 \\
\hline $\mathrm{Fe}^{3+}$ & 0,091 & 0,129 & - & 0,032 & 0,038 & 0.055 & 0,065 \\
\hline Ti & - & - & 0,004 & 0,027 & - & - & 0,060 \\
\hline $\mathbf{M g}$ & 0,033 & 0,023 & - & - & - & 0,008 & 0,005 \\
\hline $\mathrm{Na}$ & 1,513 & 9,553 & 2,526 & 2,348 & 2,189 & 2,871 & 2,535 \\
\hline $\mathrm{Ca}$ & 2,319 & 2,174 & 1,411 & 1.075 & 1,659 & 1,096 & 0,998 \\
\hline K & 0.135 & 0,164 & 0,055 & - & 0,053 & 0,127 & 0.295 \\
\hline $\mathrm{Ba}$ & & & 0,001 & 0,021 & - & - & - \\
\hline $\mathrm{Sr}$ & & & 0,024 & 0,019 & 0,033 & 0,020 & 0,020 \\
\hline TOTAL & 20,02 & 20,07 & 20,00 & 19,62 & 19,98 & 20,06 & 20,03 \\
\hline $\mathrm{O}^{2-}$ & 32,00 & 32,00 & 32,00 & 32,00 & 32,00 & 32,00 & 32,00 \\
\hline Or & 3,41 & 4,22 & 1,38 & - & 1.36 & 3,11 & 7,73 \\
\hline $\mathrm{Ab}$ & 38,09 & 39,87 & 63,23 & 68,55 & 56,06 & 70,09 & 66,18 \\
\hline An & 58,49 & 55,91 & 35,39 & 31,45 & 42,57 & 26,80 & 26,09 \\
\hline
\end{tabular}

- não detectado

i) mistura de magmas: as diferentes populações de fenocristais decorrem da mistura de magmas composicionalmente contrastantes, sendo nestes casos observadas variações significativas nos teores de An entre os cristais ou mesmo no fenocristal isolado (Dungan \& Rhodes 1978; Tsuchiyama 1985; Halsor 1989). A presença de outras fases minerais deveria também indicar o fenómeno de mistura, como $p$. ex, piroxênios ou fenocristais de quartzo, se presentes (Kontak et al. 1986). Nenhum destes aspectos foi encontrado nas rochas andesíticas estudadas;

ii) origem por assimilação: os plagioclásios são resultantes da assimilação de rochas encaixantes, tendo neste caso os fenocristais de plagioclásio o status de xenocristais (Prostka 1973; Gest \& McBirney 1979). Esta hipótese não explica a similaridade nos conteúdos de An, Sr e Ba observados tanto nos fenocristais euédricos como nos irregulares, porém auxilia na compreensão sobre a origem dos grãos arredondados de plagioclásio. Tais cristais contrastam, em composição, com as populações anteriores por atingirem um teor máximo de Anso. Ocorrem em percentagem muito baixa (1\%) entre os fenocristais e apresentam um fraturamento dendrítico, concentrado em seu núcleo, sugestivo de um processo de fusão, conforme estabelecido experimentalmente por Tsuchiyama \& Takahashi (1983). Na ausência de feições texturais que sugiram um mecanismo de mistura de magmas na génese das rochas andesíticas de Lavras do Sul, é razoável se admitir que estes grãos tenham resultado de um mecanismo de assimilação das rochas encaixantes;

iii) texturas de desequilíbrio relacionadas a um processo de rápida descompressão: neste caso, as feições de desequilíbrio, descritas para os fenocristais de plagioclásio, seriam originadas a partir de um fenómeno de reabsorção (Vance 1969; Stormer 1972). A partir desta hipótese, Nelson \& Montana (1992) utilizaram experimentalmente um andesito alto potássio e constataram que os fenocristais de plagioclásio de rochas vulcânicas intermediárias, cristalizados parcialmente em profundidade, podem sofrer reabsorção. Este fenómeno, de acordo com estes autores, seria originado pela rápida descompressão, quando a taxa de ascensão magmática supera a perda de calor. Neste experimento foram identificadas duas populações distintas de fenocristais de plagioclásio: i) uma euédrica a subédrica, com uma textura em peneira discreta, ii) e outra anédrica, acompanhada de uma textura em peneira bem desenvolvida, com uma zonação oscilatória, originada antes do fenómeno de reabsorção. Observaram também que os teores de An são levemente superiores no grupo euédrico. Esta evidência permite explicar, no caso de Lavras do Sul, a presença de fenocristais euédricos e anédricos zonados, bem como a superposição parcial nos teores de An e os valores mais elevados desta molécula nos primeiros. Alternativamente poder-se-ia sugerir que a dissolução do clinopiroxênio cálcico, devido a instabilidade desta fase em condições de baixa pressão, acompanhada da cristalização de fenocristais de plagioclásio, seria responsável pelo conteúdo mais elevado de An dos grãos euédricos. Contudo, a natureza precoce destes cristais, aliada aos aspectos texturais observados nos clinopiroxênios das rochas andesíticas, sugere condições de equilíbrio. Tal fato favorece a hipótese de que o fenómeno de reabsorção tenha originado o grupo de fenocristais anédricos. Deve-se, neste caso, admitir intervalos de despressurização não superiores a $3 \mathrm{~Kb}$, que dissolveriam os clinopiroxênios. A baixa proporção entre o conteúdo de fenocristais anédricos, com textura em peneira, e os fenocristais euédricos, sugere uma taxa de reabsorção relativamente baixa, o que indicaria, segundo os dados de Nelson \& Montana (1992), um intervalo de despressurização da ordem de 2-3 Kb. Esta sugestão é coerente com as condições naturais previstas para os sistemas vulcânicos, cujas taxas de ascensão magmática esperadas são da ordem de $0,5 \mathrm{~m} / \mathrm{s}$ a $1,7 \mathrm{~m} / \mathrm{s}$ (Spera 1980; Klein et al. 1987);

iv) irregularidades nos fenocristais de plagioclásio relacionadas aos efeitos cinéticos de cristalização: a morfologia dos cristais anédricos alongados (esqueletais) está relacionada ao aumento na taxa de resfriamento do magma (Kuo \& Kirkpatrick 1982). Este fenómeno deve ter atuado juntamente com a reabsorção e deve ter promovido a forte zonação oscilatória observada nos fenocristais anédricos das rochas intermediárias da ASLS.

O plagioclásio da matriz possui teores de $A_{27-40}$ e está acompanhado, de forma subordinada, por feldspato potássico, quimicamente compatível com sanidina e, de forma mais rara, por anortoclásio. Os dados relativos a esta população, juntamente com os dos fenocristais tabulares e irregulares são projetados para o sistema $\mathrm{Ab}-\mathrm{An}-\mathrm{Or}$ na figura 3.

Os teores de ortoclásio nos fenocristais euédricos e anédricos variam de $3 \%$ a $5 \%$, sendo, no entanto, mais elevados nos cristais da matriz. O incremento dos teores nestes últimos é coerente com a observação de Carmichael et al (1974), que constataram o aumento no conteúdo de Or nos plagioclásios cristalizados em equilíbrio com sanidina. $\mathrm{O}$ conteúdo de $\mathrm{Or}$ nos cristais assimilados é da ordem de $1 \%$ e pode estar relacionado ao mecanismo de fusão destes grãos, devido a tendência do $\mathrm{K}$ de concentrar-se no líquido (Tsuchiyama \& Takahashi 1983; Tsuchiyama 1985), ou mesmo a um baixo conteúdo original deste óxido.

$\mathrm{O} \mathrm{FeO}$ possui valores ligeiramente mais elevados nos cristais da matriz, enquanto o $\mathrm{MgO}$ possui uma moda de $\mathrm{O}, 1 \%$, independente da população de plagioclásio. Smith (1974) correlacionou os conteúdos de $\mathrm{Fe}$ e $\mathrm{Mg}$ dos plagioclásios com a temperatura de cristalização e com a composição do magma. No caso dos plagioclásios das rochas andesíticas, pode-se constatar apenas que os cristais da matriz, de temperatura de cristalização mais baixa, concentram os valores mais elevados 
de $\mathrm{FeO}$ e que não existe uma correlação entre $\mathrm{Mg} / \mathrm{Mg}+\mathrm{Fe}$ dessas rochas com o teor de An.

Os teores de $\mathrm{Ba}$ e $\mathrm{Sr}$ dos feldspatos são variáveis e não correlacionáveis com o teor de An. $\mathrm{O}$ conteúdo de $\mathrm{Ba}$, na maior parte dos casos, é superior a 1000 ppm, observando-se apenas um valor anómalo, em torno de $1 \%$, em um grão de sanidina na matriz. Os teores são bastante contrastantes nos fenocristais zonados e podem refletir as diferentes etapas de reequilíbrio destes com o líquido. $\mathrm{O} \mathrm{Sr}$ tem teores acima de $2000 \mathrm{ppm}$ na maior parte dos casos, e da mesma forma que o $\mathrm{Ba}$, apresenta variações significativas destes em um mesmo grão. Conteúdos elevados de $\mathrm{Sr}$, em média $0,5 \%$, foram também observados no plagioclásio de andesitos alto potássio no graben de Colima (México) por Allan \& Carmichael (1984). Os teores destes elementos se superpõem nas populações de fenocristais anédricos e euédricos, o que fortalece a hipótese de que estas tenham sido geradas a partir de um mesmo líquido. Destaca-se ainda que os teores de $\mathrm{Sr}$ nos plagioclásios em relação aos obtidos em rocha total aproximam-se dos preditos pelos coeficientes de partição listados por Henderson (1982). Já os conteúdos de Ba nos plagioclásios são superiores aos apontados por este mesmo autor, indicando que nestes líquidos os coeficientes de partição aproximam-se da unidade. Os cristais interpretados como assimilados, possuem teores da ordem de 900 ppm de Sr e de 500 ppm de Ba.

\section{Feldspatos dos Lamprófiros Espessartíticos}

Nestas litologias, os feldspatos se restringem à matriz e, devido ao seu reduzido tamanho, foi necessária uma seleção das análises, para evitar resultados originados da superposição do material da matriz e/ou dos finos intercrescimentos de sanidina e de plagioclásio. A partir do conjunto pré-selecionado foi possível constatar o domínio de plagioclásio sobre sanidina, conforme apresentado na tabela 3 .

Os teores de An apontam para o domínio de albita ( $\left.\mathrm{An}_{-10}\right)$, seguida de duas amostras de menor expressão, compatíveis com oligoclásio $\left(\mathrm{An}_{20-25}\right)$ e andesina $\left(\mathrm{An}_{40-45}\right)$, conforme ilustrado na figura 4. Esta diversidade composicional dos plagioclásios, conforme observado por Rock (1984; 1991), é comum em lamprófiros deste tipo. O predomínio desta com-

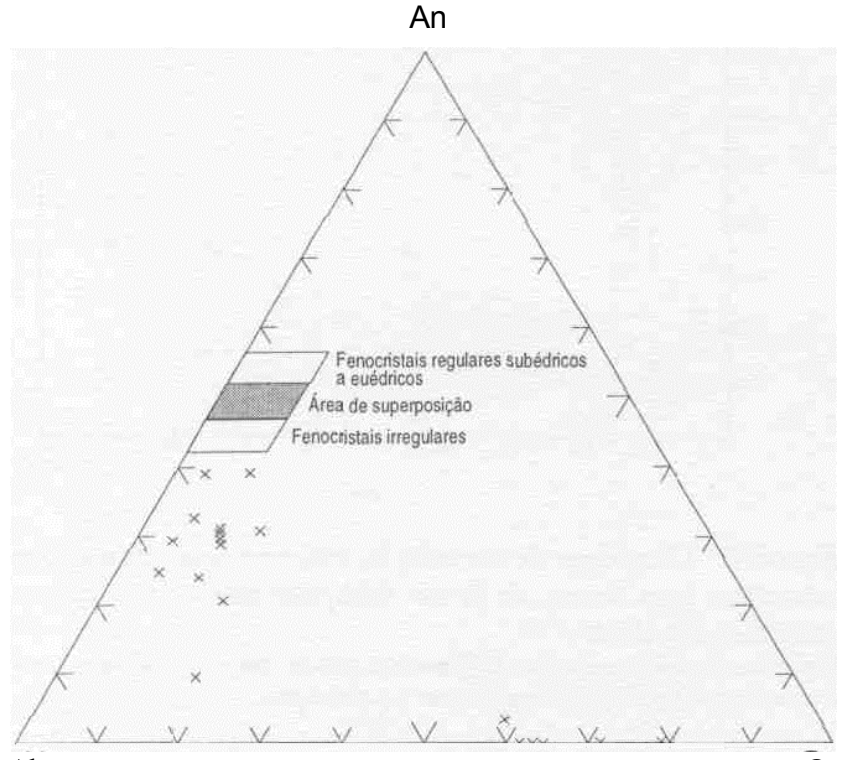

Figura 3 - Dados químicos do feldspato das rochas vulcânicas intermediárias da ASLS projetados no sistema Ab(albita)- An (anortita)- Or (ortoclásio). Microfenocristais e feldspatos da matriz $(x)$ são também projetados.

Figure 3 - Chemical data of feldspar from intermediate volcanic rocks from the Lavras do Sul Shoshonitic Association in the system Ab-An-Or. (x) = matrix microphenocrysts. posição, de acordo com Nemec (1 966), deve refletir processos de transformação do plagioclásio original. A mesma hipótese foi também admitida por Perring et al. (1989), para explicar a presença de albita na matriz de lamprófiros cálcico-alcalinos arqueanos.

Deve-se ressaltar, nesses casos, a dificuldade em classificar estas rochas, de acordo com os critérios de Streckeisen (1979), como espessartitos ou vogesitos. Esta questão é minimizada para os lamprófiros de Lavras do Sul por possuírem, na maior parte dos casos, albita com An 5. No entanto, estas composições são consideradas como decorrentes da ação de voláteis, principalmente $\mathrm{CO}_{2}$, que foram responsáveis pela retirada do cálcio dos plagioclásios, reprecipitando este elemento na condição de uma fina película de carbonato sobre ou entre os grãos. A presença de oligoclásio, no entanto, pode ser explicada por duas maneiras distintas:

i) decorrente de um estágio intermediário entre a composição original, provavelmente andesina, e a geração de albita, ou ii) cristalização tardia desta fase, sendo, neste caso, o oligocásio originado em temperaturas mais baixas e, possivelmente, em equilíbrio com a sanidina. A figura 5 sugere um equilíbrio entre o oligoclásio mais enriquecidos na molécula de Or e o líquido final. Os demais parecem convergir em direção ao vértice da $\mathrm{Ab}$, sugerindo a modificação no teor original de An.

O número de análises disponíveis de plagioclásio de lamprófiros espessartíticos impede uma comparação mais detalhada. No entanto, a sugestão de que a andesina represente o plagioclásio original coincide com os dados de Watkeys \& Armstrong(1985).

Os conteúdos de $\mathrm{Sr}$ e $\mathrm{Ba}$ do feldspato são elevados, porém variáveis. $\mathrm{O}$ primeiro possui valores, em geral, superiores a $1500 \mathrm{ppm}$, atingindo até $0,5 \%$, enquanto o Ba se concentra no intervalo de 700-2000 ppm. Os teores elevados são considerados por Rock (1991) como uma feição comum em feldspatos de lamprófiros. Estes elementos, quando comparados com os conteúdos de An, demonstram uma dispersão dos valores de $\mathrm{Ba}$ e a existência de duas populações de $\mathrm{Sr}$ (Fig. 6). Uma delas concentra a maior parte das análises, e mostra o abrupto crescimento nos teores de $\mathrm{Sr}$ com o suave incremento no teor de An. Tal correlação pode refletir a menor mobilidade do $\mathrm{Sr}$ em relação ao cálcio durante a modificação do plagioclásio original. A outra população mostra um aumento gradativo de Sr com o crescimento da molécula de An e deve representar as variações decorrentes da cristalização dos lamprófiros.

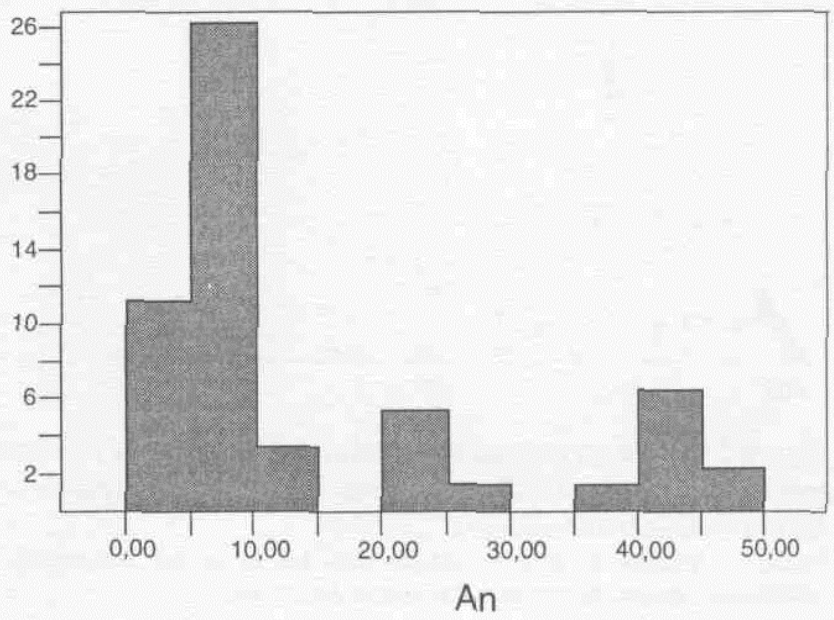

Figura 4 - Histograma dos conteúdos de An (anortita) do feldspato da matriz dos lamprófiros espessartíticos da ASLS. Número de análises - 51.

Figure 4 - Anorthite contents of groundmass feldspar from Lavras do Sul Shoshonitic Association espessartitic lamprophyres $(\mathrm{N}=51)$. 
Tabela 2 - Composição química e fórmula estrutural (32 oxigênios) do plagioclásio dos traquiandesitos: Tb=fenocristal tabular maclado; Ir-fenocristal irregular com zonações; $m$ = feldspato da matriz

Table 2 - Chemical composition and structural formula (32 oxygens) of plagioclase from LSSA trachyandesites. $\mathrm{Tb}=$ tabular twined phenocryst, Ir $=$ zoned irregular phenocryst, $m=$ matrix feldspar.

\begin{tabular}{|c|c|c|c|c|c|c|c|c|c|c|c|c|c|c|c|c|c|c|c|c|c|}
\hline & $\begin{array}{r}\mathrm{AN2} \\
\mathrm{Tb} \\
\end{array}$ & $\mathrm{Tb}$ & Tb & $\mathrm{Tb}$ & $\begin{array}{r}\text { TAN2 } \\
\text { Tb } \\
\end{array}$ & $\mathrm{Tb}$ & $\mathrm{Tb}$ & $\begin{array}{r}\text { TAN21 } \\
\text { Th }\end{array}$ & $\begin{array}{r}6 \mathrm{TAN} 2 \\
\mathrm{~Tb} \\
\end{array}$ & $\begin{array}{r}\text { STAN2 } \\
\text { Tb } \\
\end{array}$ & $\begin{array}{r}\text { TAN2 } \\
\mathrm{Tb} \\
\end{array}$ & Ir. & $\begin{array}{l}\text { AN217 } \\
\text { if. }\end{array}$ & $\begin{array}{c}\text { TAN216 } \\
\text { Ir. }\end{array}$ & $\begin{array}{c}\text { TAN216 } \\
\text { Ir } \\
\end{array}$ & $\begin{array}{c}\text { TAN216 } \\
\text { Ir. } \\
\end{array}$ & $\begin{array}{c}\text { TAN216 } \\
\text { Ir. }\end{array}$ & $\begin{array}{c}\text { TAN210 } \\
\mathrm{m}\end{array}$ & $\begin{array}{c}\text { TAND15 } \\
\mathrm{m}\end{array}$ & $\begin{array}{c}\text { TAN217 } \\
\mathrm{m}\end{array}$ & $\begin{array}{c}\text { raN217 } \\
m\end{array}$ \\
\hline $\mathrm{SiO}_{2}$ & 54,47 & 54,94 & 55,14 & 54,98 & 54.67 & 55,03 & 55,21 & 55,38 & 55.15 & 55,21 & 55,38 & 55,22 & 55,34 & 55,70 & 55,42 & 55.70 & 56,11 & 57,46 & 58,15 & 65,24 & 64,63 \\
\hline $\mathrm{TiO}_{2}$ & 0,02 & 0,08 & 0,07 & 0,05 & 0,02 & 0,02 & 0,12 & 0.08 & 0,01 & 0,05 & 0,01 & 0,09 & 0,04 & 0,01 & 0,10 & .08 & 1,03 & 0,17 & 0,11 & 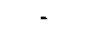 & - \\
\hline $\mathrm{Al}_{2} \mathrm{O}_{3}$ & 28,89 & 28,20 & 28,35 & 28,48 & 28,65 & 28,32 & 28,14 & 27,44 & 27,70 & 27.73 & 27,58 & 27,04 & 27,68 & 28.08 & 28,23 & 27.88 & 27.30 & 24,92 & 25,65 & 19,00 & 19,13 \\
\hline $\mathrm{FeO}$ & 0.52 & 0.47 & 0.63 & 0,47 & 0,47 & 0.51 & 0,41 & 0.43 & 0,42 & 0,43 & 0.44 & 0.48 & 0,40 & 0.46 & 0,35 & 0.42 & 0,50 & 0,81 & 0,28 & 0,02 & . \\
\hline $\mathrm{MgO}$ & 0,08 & 0,05 & 0,06 & 0,05 & 0,05 & 0,06 & 0,06 & 0,05 & 0,06 & 0,05 & 0,04 & 0,05 & $0,0 \mathrm{t}$ & 0, & 0,08 & ,06 & 0.08 & - & 0,23 & 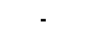 & - \\
\hline $\mathrm{MnO}$ & 0,02 & - & 0,04 & . & 0,01 & 0,04 & - & . & 0,00 & 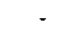 & 0,01 & 0,04 & 0,02 & & - & 0,02 & - & 0.32 & 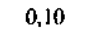 & 0,09 & - \\
\hline $\mathrm{CaO}$ & 11,02 & 10,64 & 0.58 & 10,64 & 10.34 & 10,41 & 10,36 & 10,25 & 10.24 & 10.10 & 9,94 & 9,90 & 9,88 & 10,03 & 10,04 & 10,00 & 1,37 & 32 & 12 & 0,16 & 0.11 \\
\hline $\mathrm{Na}_{3} \mathrm{O}$ & 4,81 & 4,85 & 4,89 & 5,02 & 4,90 & 4,93 & 5.03 & 5,06 & 5,18 & 5,08 & 5,04 & 4,95 & 5,05 & 5,13 & 5,22 & 5,29 & 5,54 & 6.64 & 6.51 & 3,98 & 3.70 \\
\hline $\mathrm{K}_{2} \mathrm{O}$ & 0,54 & 0.58 & 0,58 & 0,62 & 0,64 & 0.66 & 0,63 & 0,66 & 0,64 & 0,71 & 0.69 & 0,77 & 0,70 & 0, & 0.70 & 73 & .75 & 1 & 66 & 10,42 & 10,31 \\
\hline TAL & 100,38 & 99,82 & 30,33 & 100,31 & 99.73 & 99,97 & 9.95 & 99,34 & 99,41 & 99.36 & 99,13 & 98,54 & 99,17 & 100,27 & 100,14 & 100,17 & 99,68 & 98.96 & 99,69 & 98,91 & 97,88 \\
\hline $\mathrm{Ba}$ & 338 & 1682 & - & 712 & 2296 & 1371 & 1344 & 2884 & - & 3978 & 1397 & 1682 & 632 & 881 & $\cdot$ & 899 & 1460 & 3900 & 400 & 9434 & 6319 \\
\hline Sr & 3066 & 2772 & 3293 & 3310 & 3158 & 2579 & 2428 & 2831 & 2377 & 2982 & 2554 & 3116 & 2822 & 3553 & 3167 & 3167 & 2663 & 1100 & 2160 & 3780 & 3360 \\
\hline K & 0,124 & 0.135 & 0,134 & 0,142 & 48 & גוסוס & 140 & (ט) & 47 & 0,165 & $0.16 \mathrm{I}$ & 0,180 & 0,101 & & 8,101 & 年 & & 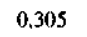 & & 2,420 & 2,421 \\
\hline $\mathrm{Na}$ & 1,680 & 1,700 & 1,705 & 1,752 & 1,716 & 1.725 & 1,760 & 1.779 & 1,823 & 1,786 & 1.776 & 1.755 & 1.777 & 1,788 & 1.821 & 1,847 & 1,939 & 2.346 & 2,269 & 1,408 & 1,320 \\
\hline $\mathrm{Ca}$ & 2,126 & 2,060 & 2,041 & 2,052 & 2,002 & 2,013 & 2,002 & 1,991 & 1.992 & 1,962 & 1,934 & 1,939 & 1,922 & 1,932 & 1,936 & 1.928 & 1,812 & 1,234 & 1,564 & 0,031 & 0,022 \\
\hline $\mathrm{Fe}$ & 0.078 & 0,072 & 0,094 & 0,070 & 0,071 & 0.077 & 0,061 & 0,066 & 0,064 & 0,066 & 0,067 & 0,073 & 0,061 & 0,070 & 0.053 & 0,063 & 0,075 & 0.123 & 0.042 & 0.003 & - \\
\hline $\mathrm{Mg}$ & 0.022 & 0.014 & 0.017 & 0,014 & 0.014 & 016 & 0.015 & 0,013 & 0,016 & 0,013 & $0,0 \mathrm{H}$ & 0,013 & 0 . & 0 & 0,020 & 0.017 & 2 & 0,087 & 0,061 & - & 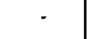 \\
\hline$\pi i$ & 0.003 & 0.011 & 0,009 & 0,007 & 0,003 & 0,003 & 0,016 & 0,011 & 0,002 & 0,007 & 0,001 & 0.012 & 0.005 & 0,002 & 0,014 & 0,011 & 0.004 & 0,023 & 0,015 & - & $=$ \\
\hline $\mathrm{Al}$ & 6,134 & 6,006 & 6,014 & 6,042 & 6,103 & 6,026 & 5,983 & 5,865 & 5,925 & 5,924 & 5,903 & 5,826 & 5,924 & 5.947 & 5,988 & 5.913 & 5.811 & 5.350 & 5.438 & 4,084 & 4,149 \\
\hline $\mathrm{Ba}$ & 0,003 & 0.013 & - & 0,006 & 0.018 & $0,01 \mathrm{I}$ & 0,011 & 0,023 & - & 0,032 & 0,011 & 0.014 & 0.005 & 0,007 & - & 0,007 & 0,012 & 0,028 & 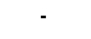 & 0,076 & 0,051 \\
\hline $\mathrm{Sr}$ & 0,038 & 0,035 & 0,041 & 0,041 & 0,039 & 0,032 & 0,030 & 0.035 & 0,030 & 0,037 & 0,032 & 0,039 & 0,035 & 0,044 & 0,039 & 0,039 & 0.033 & 0,011 & 0,027 & 0,048 & 0,043 \\
\hline $\mathrm{Si}$ & 9,812 & 9,929 & 9,924 & 9,896 & 9.882 & 9,934 & 9,961 & 10,043 & 10,010 & 10.0088 & 10,059 & 10,095 & 10,048 & 10.011 & 9.975 & 10,024 & 10.133 & $t 0,560$ & 10.460 & 11,900 & 11.895 \\
\hline OTAL & 20,02 & 19.97 & 19,98 & 20.02 & 20,00 & 19,99 & 19,98 & 19,98 & 20,01 & 20.00 & 19,96 & 19.95 & 19,95 & 19.99 & 20,01 & 20,02 & 20,01 & 20,07 & 20.01 & 19,97 & 19.90 \\
\hline $\mathrm{O}^{2}$ & 32,00 & 32,00 & 32.00 & 32,00 & 32,00 & 32,00 & 32,00 & 32,00 & 32,00 & 32,00 & 32,00 & 32,00 & 32,00 & 32,00 & 32,00 & 32,00 & 32,00 & 32.00 & 32,00 & 32,00 & 32,00 \\
\hline Or & 3,16 & 3,47 & 3,45 & 3,60 & 3,84 & 3,90 & 3,71 & 3,90 & 3,76 & 4,22 & 4,15 & 4,66 & 4,19 & 4,40 & 4,13 & 4,25 & 4,38 & 7,87 & 3,25 & 62.81 & 64,39 \\
\hline$A b$ & 42.70 & 43,60 & 43,90 & 44,36 & 44,35 & 44,30 & 45.01 & 45.31 & 45.95 & 45,61 & 45,84 & 45,25 & 45,99 & 45,90 & 46,42 & 46,80 & 49.38 & 60,33 & 57,23 & 36,38 & 35,03 \\
\hline An & 54,14 & 52,93 & 2,65 & 52,04 & 1,82 & 1,81 & 1.28 & 50,80 & 50,29 & 50,17 & 50,00 & 50,09 & 49,83 & 44.70 & 49,46 & 48.95 & 46,24 & 31.80 & 39.52 & 0,81 & 0.58 \\
\hline
\end{tabular}

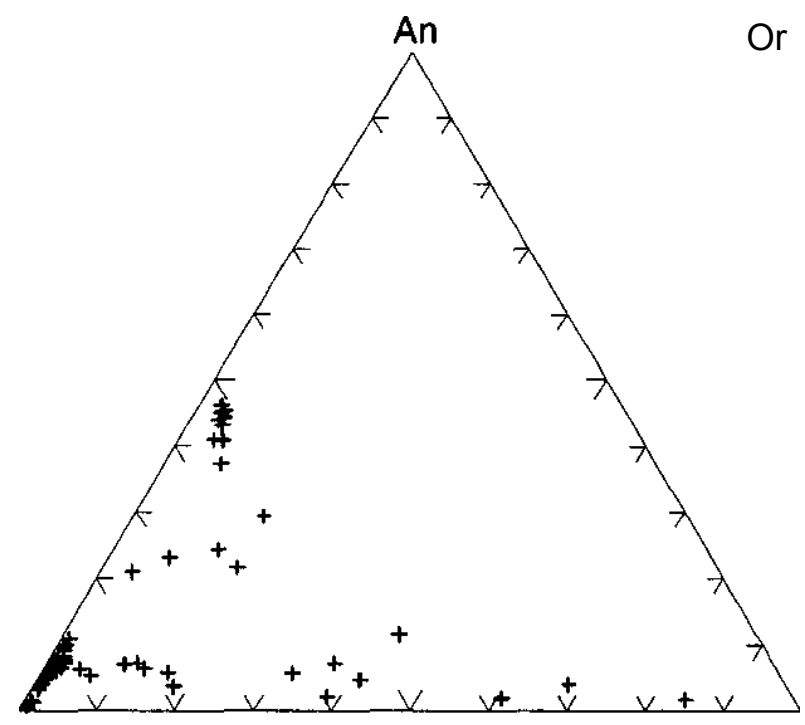

$\mathrm{Ab}$

Figura 5 - Análises por microssonda de feldspato das rochas espessartíticas da ASLS projetados no sistema Ab(albita)An(anortita)-Or(ortoclásio).

Figure 5 - Microprobe data of feldspar from Lavras do Sul Shoshonitic Association espessartitic rocks in the system Ab-An-Or.

A comparação entre os teores de $\mathrm{Ba}$ e $\mathrm{Sr}$, embora mostre uma dispersão, sugere uma correlação negativa (Fig. 7). Este dado, adicionado ao fato de que os valores mais elevados de Ba foram obtidos nos plagioclásios com um maior conteúdo

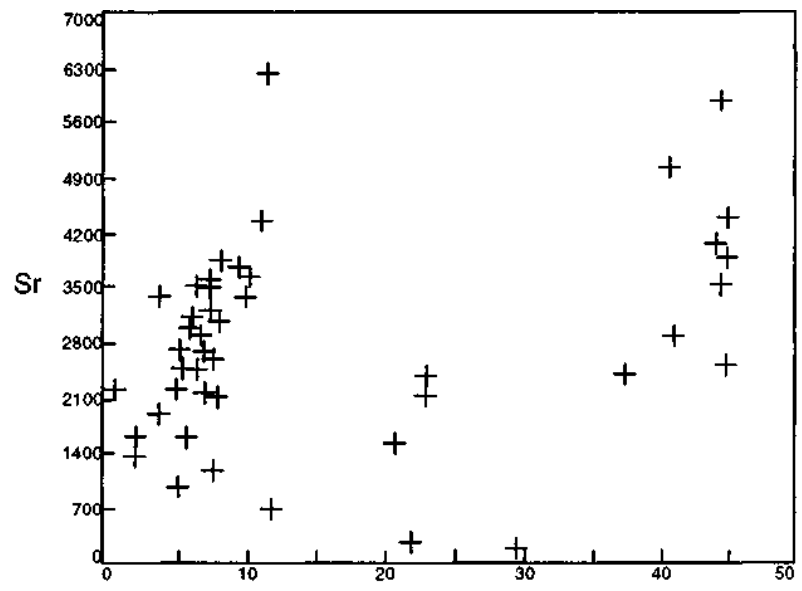

An

Figura 6 - Diagrama de correlação entre os conteúdos de An (anortita) e os teores de $\mathrm{Sr}$ do feldspato das rochas espessartiticas da ASLS.

Figure 6 - Correlation diagram for anorthite and $\mathrm{Sr}$ contents in feldspar from Lavras do Sul Shoshonitic Association lamprophyres.

de Or, demonstra que a substituição $\mathrm{Ba}-\mathrm{K}^{+}$domina na medida em que esta fase torna-se mais enriquecida na molécula de ortoclásio,

OLIVINA DAS ROCHAS VULCÂNICAS BÁSICAS E

INTERMEDIÁRIAS A olivina ocorre nas rochas básicas e de forma subordinada, nas composições intermediárias até 
Tabela 3 - Composição química e fórmula estrutural (32 oxigênios) do feldspato dos lamprófiros espessartíticos da ASLS. Fab = fenocristal alterado, análise da borda; $F a_{c}=$ fenocristal alterado análise do centro; $M F=$ microfenocristal; $M F b=$ borda de microfenocristal; $M F c=$ centro de microfenocristal.

Table 3 - Chemical composition and structural formula (32 oxygens) of feldspar from LSSA espessartitic lamprophyres. Fab = Altered phenocryst border; $\mathrm{Fac}=$ altered phenocryst, core; $\mathrm{Mf}=$ microphenocryst; $\mathrm{MFb}=$ microphenocryst border, $\mathrm{Mfc}=$ microphenocryst core .

\begin{tabular}{|c|c|c|c|c|c|c|c|}
\hline & $\begin{array}{r}14230 \\
F_{3} \\
\end{array}$ & 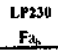 & $\begin{array}{c}12130 \\
F^{2}\end{array}$ & 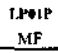 & $\begin{array}{l}\begin{array}{l}L P 239 \\
M F\end{array} \\
\end{array}$ & $\begin{array}{l}\text { LP?360 } \\
\text { MEF }\end{array}$ & $\begin{array}{l}\text { I.FAIr } \\
\text { MP }\end{array}$ \\
\hline $\mathrm{SiO}_{3}$ & $6 f, 23$ & 66,51 & 66,98 & 56,22 & $66.41)$ & 65.59 & 59.99 \\
\hline $\mathrm{TiO}_{2}$ & $(1,01)$ & 0,01 & & 0.34 & 0.03 & 0.13 & 3,34 \\
\hline$A b_{0} O_{2}$ & 21.85 & 21.27 & 21.80 & 27.54 & 21,42 & 21,34 & 25.93 \\
\hline $\mathrm{FeO}$ & 0,02 & 0,04 & 0,015 & 01,23 & $\cdot$ & 0.55 & 0.31 \\
\hline $\mathrm{MgO}$ & 0,001 & 0,02 & 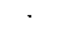 & 0.115 & 0.02 & 0,15 & 0,04 \\
\hline MnO & - & 0.16 & 0.01 & - & - & - & - \\
\hline $\mathrm{CrrO}$ & 2,22 & 1.62 & 1.59 & 9,24 & 2,07 & 1.48. & 4.55 \\
\hline $\mathrm{NapO}$ & 10.15 & 10,54 & $10,4 \%$ & 5.87 & 30,44 & 9,19 & 7.58 \\
\hline $\mathrm{K}_{2} \mathrm{U}$ & 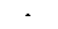 & ONy & 0,106 & 0,56 & 0.05 & 1.89 & 1,36 \\
\hline TOTAL & $\operatorname{l10} 0,48$ & 100,25 & 1401,98 & 94,74 & 100,42 & 190.19 & $(\mathrm{~m}) .11$ \\
\hline Sr & 4.3611 & 2136 & 3164 & 4424 & 3640 & 3176 & 2416 \\
\hline Si & $11.94 \pi$ & 11.6 .59 & $11.001 \%$ & 10,117 & 15.587 & $11.5 \% 2$ & I11,669 \\
\hline Al & 4,487 & 4,746 & 4,453 & 5,841 & 4,4460 & 4,443 & 3,436 \\
\hline $\mathrm{Mg}$ & 0, (101)I & $0,0\left(x_{14}\right.$ & - & 0,014 & 0.0015 & 0,040 & $0,(t+1)$ \\
\hline $\mathrm{Fe}^{3+}$ & H. & 0,016 & $0, \mathrm{~m} / \mathrm{T}$ & $0,0,34$ & . & 10.0855 & 0,0466 \\
\hline $\mathrm{Na}$ & 3.428 & 3.576 & 3.525 & 2,040 & .353 & 3.122 & 2.615 \\
\hline Ca & $0,41,5$ & 0,304 & 0,295 & 1,781 & $0.38 \mathrm{Bg}$ & 0,279 & 01,867 \\
\hline$\kappa$ & & 0,021 & 10.014 & $0, \$ 28$ & 0.01110 & 0,426 & $01.309 \%$ \\
\hline$T_{i}$ & 0,401 & $0,(x) 1$ & . & $0,0,014$ & $0.0,0 / 4$ & 0,0015 & 0,0145 \\
\hline St & 0,1055 & 10,027 & $0.03 \%$ & $1.05 \%$ & 0,046 & $\{,, 1,44\}$ & 0,031 \\
\hline TOTAL & 14,93 & 14.96 & 19.94 & 20.11 .5 & 19,98 & 19.94 & 2010.1. \\
\hline $0^{*}$ & 32,040 & $32.40 \mathrm{r}$ & $\$ 2,000$ & $32,(00)$ & 32,101 & $32,00)$ & 32001 \\
\hline or & - & 0,53 & 0.37 & 3.25 & 0.26 & 11.16 & $\$, 17$ \\
\hline Ab & $\$ 9.18$ & 91,67 & 91,93 & 51.74 & 89,89 & 81.55 & $t-8.43$ \\
\hline An & {$[11+82$} & 7.81 & 7.70 & 45,115 & 9.8 .5 & 7.29 & 22,941 \\
\hline
\end{tabular}

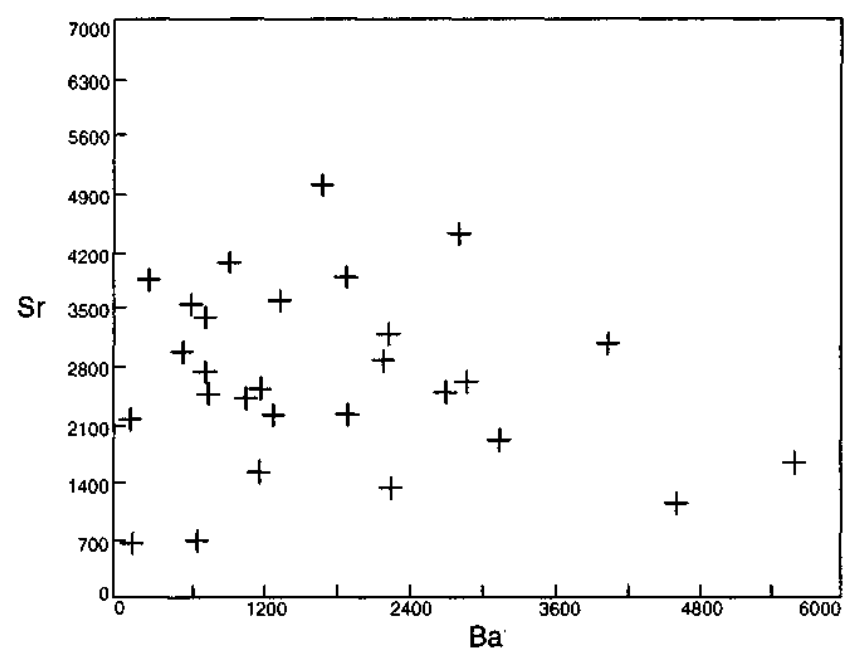

Figura 7-Diagrama de correlação entre os teores de Sr versus Ba do feldspato dos lamprófiros da ASLS.

Figure 7 - Correlation diagram for $\mathrm{Ba}$ and $\mathrm{Sr}$ contents in feldspar from Lavras do Sul Shoshonitic Association lamprophyres.

$56 \%$ de $\mathrm{SiC}_{2}$ da ASLS. Devido a alteração geralmente presente na olivina, responsável pela serpentinização e carbonatação, foram selecionadas para análise de química mineral duas rochas básicas e duas rochas intermediárias, que preservaram esta fase. As olivinas possuem como característica principal uma homogeneidade composicional com teor médio de $\mathrm{Fo}_{67}$ nas rochas básicas e de $\mathrm{Fo}_{62}$ na composição intermediária (Tab. 4). Em ambos os grupos, a diminuição de Fo, quando ocorre, é da ordem de $1 \%$ a $2 \%$, do núcleo em direção às bordas.
Tabela 4 - Composição química e fórmula estrutural (4 oxigênios) da olivina dos traquibasaltos (TBA) e traqui-andesitos (TAND) da ASLS. MF= microfenocristal; $b=$ análise da borda de microfenocristal; c- análise do centro do microfenocristal.

Table 4 - Chemical composition and structural formula (4 oxygens) of olivine from LSSA trachybasalts (TBA) and trachyandesites (TAND). MF = microphenocryst, $\mathrm{b}=$ microphenocryst border; $\mathrm{c}=$ microphenocryst core.

\begin{tabular}{|c|c|c|c|c|c|c|c|}
\hline \multirow[t]{2}{*}{ F peso } & \multicolumn{4}{|c|}{ TAND106 TAND100 'TANDIA6 TAND106 } & \multirow{2}{*}{$\begin{array}{c}\text { TBA07 } \\
\text { MFb }\end{array}$} & \multirow{2}{*}{$\begin{array}{c}\text { TBAOT } \\
\text { MFC }\end{array}$} & \multirow{2}{*}{$\begin{array}{c}\text { TANDIN } \\
\text { MFFC }\end{array}$} \\
\hline & MF & MF & $\mathrm{MFb}$ & MFb & & & \\
\hline $\mathrm{SiO}_{2}$ & 36,45 & 36,36 & 35,83 & 36,13 & 37,20 & 37,24 & 36.69 \\
\hline $\mathrm{Cr}_{2} \mathrm{O}_{2}$ & - & - & - & 0,01 & 0,08 & 0.06 & 0,06 \\
\hline FeO & 32,16 & 32.20 & $32 ; 60$ & 32,30 & 29.16 & 28,10 & 31,43 \\
\hline MnO & 0,55 & 0,68 & 0,59 & 0,58 & 0,27 & 0,24 & 0,65 \\
\hline $\mathrm{NIO}$ & . & - & . & 0,08 & . & 0,02 & . \\
\hline $\mathrm{MgO}$ & 30,56 & 30,63 & 29.89 & 30,44 & 32.72 & 34,00 & 30,84 \\
\hline $\mathrm{CaO}$ & 0,26 & 0,17 & 0,28 & 0,19 & 0,20 & 0.19 & 0,21 \\
\hline TOTAL & 99,98 & 100,04 & 99.19 & 99,73 & 99,63 & 99,85 & 99,93 \\
\hline$S \mathrm{j}$ & $1,0 \times 10$ & $1,(1) 00$ & 0,990 & 0,990 & $1,(0) 0$ & 1,000 & 1,060 \\
\hline $\mathrm{Mg}$ & 1.250 & 1,250 & 1,240 & 1,250 & 1,320 & 1,360 & 1,260 \\
\hline $\mathrm{Fe}^{\mathrm{I+}}$ & 0.740 & 0,740 & 0.760 & 0,740 & 0,660 & 0,630 & 0,720 \\
\hline Mn & 0,010 & 0,020 & 0,010 & 0,010 & 0,010 & 0,010 & 0,020 \\
\hline $\mathrm{Ca}$ & 0,010 & $0,(0) 00$ & $0,010)$ & 0,010 & 0,010 & 0,010 & 0,010 \\
\hline TOTAL & $3,00 \mathrm{KJ}$ & 3,000 & 3.010 & 3,010 & 2,990 & $3 .(X) Y$ & 3,000 \\
\hline $0^{2-}$ & 4,000 & 4,000 & 4,0000 & 4,000 & $4(x) 0$ & 4,000 & 4,000 \\
\hline$F_{0}$, & 62 & 62 & 62 & 62 & 66 & 68 & 63 \\
\hline $\mathrm{Fa}$ & 38 & 38 & 38 & 38 & 34 & 32 & 37 \\
\hline
\end{tabular}

Ewart (1982) coloca a moda composicional de olivinas em rochas básicas shoshoníticas no intervalo $\mathrm{Fo}_{70-85}$. Desta forma, as composições dos traquibasaltos de Lavras do Sul ficam ligeiramente abaixo do limite inferior estabelecido por esse autor. A presença de olivina em rochas vulcânicas intermediárias é ainda objeto de discussão e esta fase é em muitos casos interpretada como "herdada" de líquidos básicos por processos de acumulação (Gill 1981). A observação dos teores de forsterita obtidos na olivina das rochas intermediárias $\left(\mathrm{Fo}_{62}\right)$ é compatível com um trend evolutivo normal das rochas básicas para as intermediárias da ASLS. A preservação desta fase em rochas mais evoluídas pode ser atribuída aos teores relativamente altos de $\mathrm{K}$ no magma que, segundo trabalho experimental de Kushiro (1975), ampliam o campo de estabilidade da olivina em relação ao do ortopiroxênio. Esta expansão seria uma consequência da despolimerização das composições andesíticas por cátions monovalentes, destacando-se aqui o potássio. Os conteúdos relativamente baixos de forsterita da olivina são coerentes com os conteúdos de $\mathrm{FeO}$ e $\mathrm{MgO}$ das rochas básicas e intermediárias, sendo, portanto, esta fase mineral interpretada como precoce e em equilíbrio com estas composições. No que se refere à associações shoshoníticas, olivinas com tais composições são relativamente comuns (Gest \& McBirney 1979) e composições mais magnesianas (Foys) podem representar xenocristais (Ewart 1982).

Observa-se um conteúdo relativamente elevado de $\mathrm{CaO}$ nas olivinas analisadas, com teores entre $0,17 \%$ e $0,28 \%$. Simkin \& Smith (1970) sugerem que a presença de cálcio em olivinas está relacionada ao ambiente de cristalização das rochas, com tendência a uma maior concentração deste elemento em rochas vulcânicas. $\mathrm{O}$ teor de cálcio pode também indicar as condições de pressão em que esta fase cristalizou. De acordo com estudos de Simkin \& Smith (1970) e Deer et al. (1982), a solubilidade do cálcio na forsterita decresce com o aumento da pressão. Esta relação, entre o conteúdo de cálcio na olivina e a pressão, deve-se, provavelmente, à dificuldade de incorporação de elementos com raio iônico superior ao do $\mathrm{Fe}, \mathrm{Mg}$ e $\mathrm{Mn}$, com o aumento da pressão. $\mathrm{O}$ conteúdo de $\mathrm{CaO}$ nas olivinas, superior a $0,19 \%$, aponta para um pressão de cristali- 
zação relativamente baixa, conforme estudos de Simkin \& Smith (1970).

Os teores de $\mathrm{NiO}$ e $\mathrm{Cr}_{2} \mathrm{O}_{3}$ são baixos, o que é coerente com o conteúdo de Fo observado nas olivinas analisadas.

$\mathrm{O} \mathrm{MnO}$ apresenta concentracões variáveis, da ordem de 0,27 a $0,76 \%$, sendo o valor máximo obtido na olivina que acusou o teor mais elevado de $\mathrm{CaO}$. Estes valores de $\mathrm{MnO}$ concordam com as variações observadas por Deer et al. (1982) em olivinas de rochas vulcânicas e hipabissais, básicas a intermediárias. Segundo estes mesmos autores, o conteúdo de $\mathrm{MnO}$ das olivinas parece estar mais condicionado pela composição dos líquidos magmáticos do que pelas condições específicas de pressão e temperatura.

As condições de pressão envolvidas na formação das olivinas da ASLS podem ser inferidas a partir dos dados texturais e químicos obtidos, que sugerem uma cristalização precoce desta fase, seguida de clinopiroxênio e plagioclásio. Esta associação mineral em líquidos básicos, ocorre sob uma pressão total, no ambiente de cristalização inferior a $10 \mathrm{~Kb}$. Em pressões superiores, o par olivina + plagioclásio reage para produzir ortopiroxênio + clinopiroxênio + espinélio (Kushiro \& Yoder 1966). Estes dados concordam com os experimentos de Green (1982) para composições semelhantes, que limitam a presença de olivina + clinopiroxênio + plagioclásio até cerca

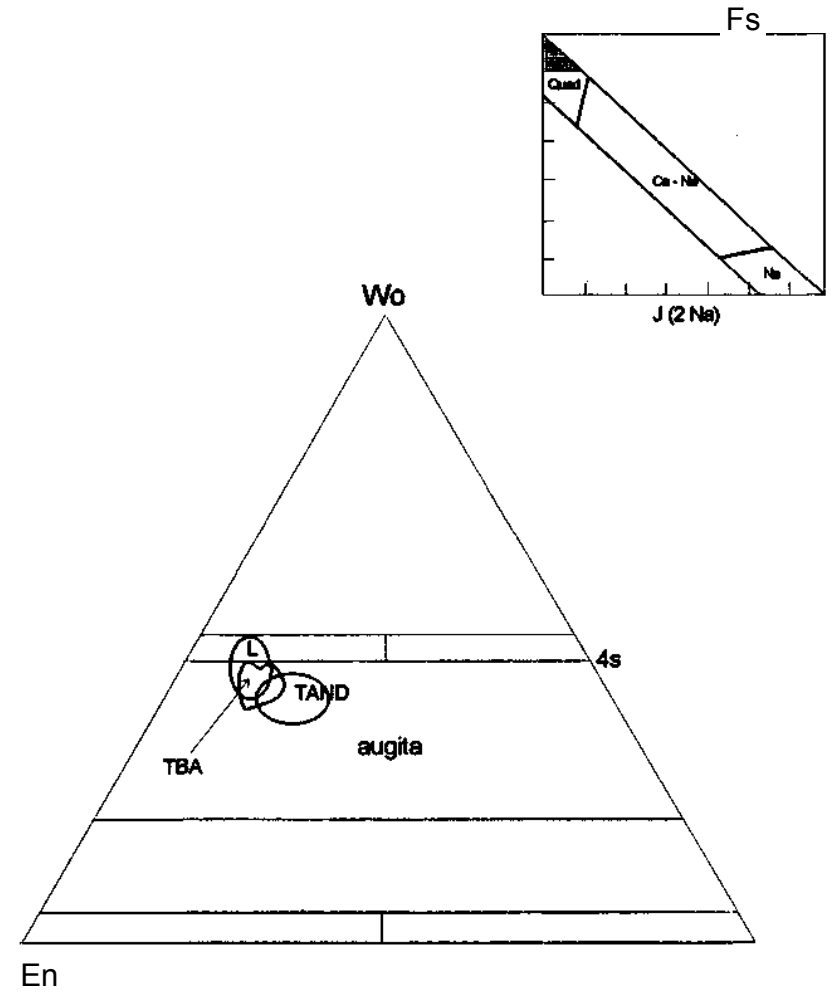

Figura 8 - Classificação do clinopiroxênio das rochas da ASLS de acordo com os critérios de Morimoto (1988). Parte superior da figura ilustra uma área hachurada que concentra os dados químicos dos clinopiroxênio da ASLS no campo $Q U A D$ do sistema $J(2 \mathrm{Na})$ versus $Q\left(\mathrm{Ca}+\mathrm{Mg}+\mathrm{Fe}^{2+}\right)$. Os mesmos dados, no triângulo Wo(volastonita)-En(enstatita)Fs(ferrossilita), ocupam deforma predominante o campo da augita transicionando para diopsídio. Legenda: TBA = traquibasaltos, $T A N D=$ traqui-andesitos, $L=$ lamprófiros espessartíticos.

Figure 8 - Classification of clinopyroxene (Morimoto, 1988) of Lavras do Sul Shoshonitic Association. The superior part of the figure shows the field which concentrate the clinopyroxene data of LSSA, in the QUAD field of J (2Na) versus $\mathrm{Q}\left(\mathrm{Ca}+\mathrm{Mg}+\mathrm{Fe}^{2+}\right)$ diagram. The same data plotted in the diagram Wo-En-Fs classify the clinopyroxenes as augites to diopsides. (TBA) trachybasalts, (TAND) trachyandesites, and (L) lamprophyres. de $7 \mathrm{~Kb}$, sob condições anidras. A incorporação de até 5\% Ü2O, segundo este autor, apenas atenua o predomínio de plagioclásio próximo à liquidus.

CLINOPIROXENIOS DAS ROCHAS VULCÂNICAS E DOS LAMPRÓFIROS O clinopiroxênio ocorre em todas as rochas vulcânicas da ASLS, é acompanhado por minerais máficos, como olivina e minerais opacos nas rochas básicas e vulcânicas intermediárias e por anfibólio nos lamprófiros espessartíticos. Todas as composições determinadas enquadram-se no grupo QUAD, que reúne os piroxênios do tipo $\mathrm{Ca}-\mathrm{Mg}-\mathrm{Fe}$, de acordo com sistema de classificação proposto por Morimoto (1988). Análises representativas desta fase são apresentadas nas tabelas 5a, b, c. Segundo a classificação adotada, os clinopiroxênios da ASLS são predominantemente do tipo augita, embora algumas composições, especialmente nos lamprófiros, invadam o campo do diopsídio (Fig.8).

Independente do tipo de rocha da ASLS, o clinopiroxênio possui de forma característica, um elevado conteúdo da molécula de wolastonita (Wo) que, na maior parte dos casos, supera $40 \%$. Este dado coincide com os obtidos em clinopiroxênios de outras associações shoshoníticas (Meen 1987, Girod 1978, Villari \& Nathan 1978, Gest \& McBirney 1979, entre outros). Estes conteúdos elevados de Wo no clinopiroxênio são apontados como comuns em rochas ricas em potássio, conforme observado por Le B as (1962) e ressaltado

Tabela 5a - Composição química e fórmula estrutural (6 oxigênios) dos clinopiroxênios dos traquibasaltos da ASLS. $F=$ fenocristal; $F b=$ borda de feno cristal; $F b_{1} a F b_{n}=$ borda de fenocristal em direção ao centro (c); $F c=$ centro de fenocristal

Table 5a - Chemical composition and structural formula (6 oxygens) of clinopyroxenes from LSSA trachybasalts. $\mathrm{F}=$ phenocryst, $\mathrm{Fb}=$ phenocryst border, $b_{1}$ to $b_{n}$ phenocryst border to core (c), $\mathrm{Fe}=$ phenocryst core.

\begin{tabular}{|c|c|c|c|c|c|c|c|}
\hline & THang & TRAOH & THA12 & THAOS & THAz1" & TBA210 & TAA 210 \\
\hline & $F$ & F & $\mathbf{F}$ & $\mathrm{Fb}$ & $\mathrm{Fo}_{1}$ & $\mathrm{Fh}_{2}$ & $\mathrm{Fe}$ \\
\hline $\mathrm{SiO}_{2}$ & 52.00 & 52.30 & 51.27 & 52.33 & 50.95 & 51.62 & 51.50 \\
\hline $\mathrm{TiO}_{2}$ & 0.71 & 0.55 & 0.44 & 0.48 & 0.76 & 0.78 & 0.6 \\
\hline $\mathrm{Al}_{2} \mathrm{O}_{3}$ & 2.92 & 2.73 & 2.96 & 2.37 & 2.93 & 2.45 & 3.08 \\
\hline $\mathrm{Fe}_{2} \mathrm{O}_{3}$ & - & - & - & - & - & 0.00 & 0.00 \\
\hline $\mathrm{Cr}_{2} \mathrm{O}_{3}$ & 0.80 & 0.77 & 0.94 & 0.61 & 0.45 & 0.67 & 0.68 \\
\hline $\mathrm{FcO}$ & 5.28 & 5.75 & 6.34 & 6.12 & 7.47 & 7.12 & 6.38 \\
\hline $\mathrm{MnO}$ & 0.17 & 0,14 & 0.16 & - & 0.13 & 0,08 & 0,07 \\
\hline NiO & 0.06 & 0.00 & - & . & - & . & \\
\hline $\mathrm{MgO}$ & 16.36 & 16.45 & t6.30 & 16.79 & $15.5 \mathrm{~T}$ & 16.26 & 16.8 \\
\hline $\mathrm{CaO}$ & 20.48 & 20.46 & 19.82 & 20.18 & $20.6 \mathrm{~T}$ & 20.52 & 19.8 \\
\hline $\mathrm{Na}_{2} \mathrm{O}$ & 0.32 & 0.44 & 0.48 & 0.36 & 0.46 & 0.33 & 0.3 \\
\hline $\mathrm{K}_{2} \mathrm{O}$ & 0,02 & 0.01 & - & - & 0.01 & & 0,00 \\
\hline Total & 99.13 & 99.62 & 98.71 & 99.25 & 99.38 & 99.83 & 99.33 \\
\hline Si IV & 1.420 & 1.925 & 1.911 & 1.933 & 1.900 & 1.911 & 1.905 \\
\hline Al IV & 0.080 & 0.075 & 0,089 & 0,167 & $0.00 \mathrm{H}$ & 0.089 & 0.095 \\
\hline $\mathbf{T}$ sitc & 2.000 & 2.000 & 2.000 & 2.000 & 2.000 & 2.000 & 2.000 \\
\hline Al VI & 0.048 & 0.044 & 0.041 & 0.037 & 0.029 & 0.017 & 0.03 \\
\hline $\mathrm{Ti}$ & 0.020 & 0.015 & 0.012 & 0.013 & 0.021 & 0.022 & 0.018 \\
\hline $\mathrm{Cr}$ & 01,023 & 0.022 & 0.028 & 0.018 & 0.013 & 0.020 & 0.02 \\
\hline $\mathrm{Fe}^{2 \cdot}$ & 0.163 & 0.177 & 0.198 & 0.189 & 0.233 & 0,221 & 0.197 \\
\hline $\mathrm{Mn}^{i+}$ & 0.005 & 0.004 & 0.005 & * & 0.004 & 0.002 & 0.002 \\
\hline $\mathrm{Ni}$ & 0,002 & - & 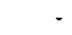 & - & - & & \\
\hline Mg & 0.9401 & $0.90,3$ & 0,906 & 0,924 & 0.866 & 0,897 & 0.921 \\
\hline $\mathrm{Ca}$ & 0,810 & 0.807 & 0.791 & 0.799 & 0.826 & 0.814 & 0.78 \\
\hline Nill & (1).023 & 0.032 & 0.034 & 0.026 & 0.033 & 0.024 & 0.028 \\
\hline K & $0.00 \mathrm{~d}$ & 0.001 & - & - & . & - & \\
\hline$M \mathbf{M}, \mathrm{M} 2$ & 1.996 & 2.005 & 2,015 & 2.006 & 2.025 & 2.016 & 2.013 \\
\hline $\mathrm{o}^{2-}$ & 6,00 & 6.00 & 6.00 & 6.00 & 6.00 & 6.00 & 6.00 \\
\hline$W_{0}$ & 43.90 & 43.00 & 42.00 & 42,00 & 43.00 & 42.00 & 41.00 \\
\hline En & 48,00 & 48.00 & 47,00 & 48.00 & 44,00 & 46.00 & 49.01 \\
\hline Fs & 9.00 & 10.00 & 11.00 & 10.00 & 13.00 & 12.00 & 10.0에 \\
\hline $\mathrm{c}^{2}+\mathrm{Mg}$ & 1.064 & 1.080 & 1.103 & 1.114 & 1.098 & 1.118 & 1.124 \\
\hline $\mathrm{mg}$ & 0.847 & 0.836 & 0.821 & 0.830 & 0.788 & 0.803 & 0.824 \\
\hline
\end{tabular}


por Gill (1981). Diferentes fatores são apontados pelo último autor para explicar tal característica:

i) temperatura de equilíbrio mais baixa para esta fase, que aumentaria a imiscibilidade do clinopiroxênio;

ii) decréscimo na atividade da sílica, que favoreceria um aumento do componente wolastonítico na augita; ou

iii) a coexistência do clinopiroxênio com anfibólio em rochas enriquecidas em álcalis, o que, conforme observado experimentalmente por Helz (1973), favoreceria o aparecimento de composições próximas à linha diopsídio-hedenbergita.

A variação composicional entre os clinopiroxênios analisados aponta para um leve incremento de ferrossilita (Fs), dos termos básicos para as rochas intermediárias (Fig. 9). Observa-se um decréscimo de mg $(\mathrm{Mg} / \mathrm{Mg}+\mathrm{Fe})$ nos clinopiroxênios das rochas básicas para as mais diferenciadas, com exceção dos lamprófiros cujos valores de mg se superpõem àqueles dos traquibasaltos. $\mathrm{O}$ conteúdo de $\mathrm{Ca}$ aumenta de modo relativo com o decréscimo de $\mathbf{m g}$ (Fig. 10). As pequenas variações químicas dentro de cada grupo sugerem um mecanismo de fracionamento do clinopiroxênio com a evolução gradual dos líquidos shoshoníticos, na região de Lavras do Sul.

Os teores de $\mathrm{Al}_{2} \mathrm{O}_{3}$ se concentram em torno de $2,5 \%$, exceto em algumas amostras básicas e intermediárias, contrastando com os clinopiroxênios de rochas shoshoníticas que, não raro, possuem teores superiores a 3\% (Pe-Piper 1984). Observa-se uma maior concentração de $\mathrm{Al}$ nas posições tetraédricas dos

Tabela $5 b$ - Composição química e fórmula estrutural (6 oxigênios) do clinopiroxênio das rochas traqui-andesíticas da ASLS. $F=$ fenocristal; $F b=$ borda de fenocristal; $F b_{1}=$ borda de fenocristal em direção ao centro(c); $F c=$ centro de fenocristal; $M F=$ microfenocristal.

Table $5 \mathrm{~b}$ - Chemical composition and structural formula (6 oxygens) of clinopyroxene from LSSA trachyandesites. $\mathrm{F}=$ phenocryst; $\mathrm{Fb}=$ phenocryst border, $b_{1}$ to $b_{n}$ phenocryst border to core (c), MF = microphenocryst.

\begin{tabular}{|c|c|c|c|c|c|c|c|}
\hline & $\begin{array}{c}\text { TANDOS } \\
\mathrm{F}\end{array}$ & $\begin{array}{c}\text { TANDJ74 } \\
\mathrm{F} \\
\end{array}$ & $\begin{array}{c}\text { TAND172 } \\
\mathrm{Fb} \\
\end{array}$ & $\begin{array}{c}\text { TAND } 109 \\
\mathrm{Fb}\end{array}$ & $\begin{array}{c}\text { TANDIR } \\
F_{1}\end{array}$ & $\begin{array}{c}\text { TAND100 } \\
\text { Fc }\end{array}$ & $\begin{array}{c}\text { TAND } 196 \\
\text { MF } \\
\end{array}$ \\
\hline $\mathrm{SiO}_{2}$ & 51,14 & 50,89 & 52,29 & 50,44 & 50,80 & 51,16 & 51,26 \\
\hline $\mathrm{TiO}_{2}$ & 0.62 & 0,87 & 0,48 & 0,970 & 0,19 & $0.6 \mathrm{t}$ & 0,66 \\
\hline $\mathrm{Al}_{2} \mathrm{O}_{3}$ & 2,34 & 2,61 & 1.78 & 3,02 & 2.42 & 2.74 & 2.22 \\
\hline $\mathrm{Cr}_{2} \mathrm{O}_{3}$ & 0.08 & 0,10 & 0,37 & 0,07 & 0.04 & 0,09 & \\
\hline $\mathrm{Fe}_{2} \mathrm{O}_{3}$ & 0,00 & 0,00 & - & + & $=$ & - & \\
\hline $\mathrm{FeO}$ & 10,88 & 10,79 & 9,48 & 10,21 & 11,82 & 9,69 & 9,31 \\
\hline $\mathrm{MnO}$ & .027 & 0.33 & 0.30 & 0,36 & 0,51 & 0.37 & 0,28 \\
\hline $\mathrm{NiO}$ & - & 0,10 & - & . & 0.02 & 0.13 & \\
\hline $\mathrm{MgO}$ & 14,90 & 14,70 & 15,06 & $\mid 4,2\}$ & 14,91 & 14,45 & 13,80 \\
\hline $\mathrm{CaO}$ & 19,52 & 19,12 & 20,39 & 19.55 & 19,08 & 20.17 & 20,19 \\
\hline $\mathrm{N}_{n_{2}} \mathrm{O}$ & 0,47 & 0,48 & 0,34 & 0,32 & 0,31 & 0,32 & 0,63 \\
\hline $\mathrm{K}_{2} \mathrm{O}$ & . & 0,02 & - & - & 0,01 & 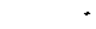 & 0,02 \\
\hline Tola] & 100,22 & 100,01 & 100,49 & 99,14 & [(10), L] & 99.73 & 98,36 \\
\hline Si IV & 1.914 & 1,907 & 1,940 & 1,903 & 1,911 & 1,916 & 1,943 \\
\hline Al IV & 0,086 & 0,093 & 0,0601 & 0,097 & 0.089 & 0,684 & 0,057 \\
\hline$T$ site & 2,000 & 2,000 & 2,000 & 2,000 & 2,000 & $2,0 \times 4$ & 2,000 \\
\hline AI VI & 0.017 & 0,023 & 0,018 & 0,037 & 0,018 & 0,037 & 0,042 \\
\hline $\mathrm{Ti}$ & 0,017 & 0,025 & 0,013 & 0,027 & 0,005 & 0,017 & 0,010 \\
\hline $\mathrm{Cr}$ & 0,002 & 0,003 & 0,011 & 0,002 & 0,001 & 0,003 & \\
\hline $\mathrm{Fe}^{2+}$ & 0.340 & 0.338 & 0.294 & 0.322 & 0,372 & 0,304 & 0,295 \\
\hline $\mathrm{Mn}^{2+}$ & 0.009 & 0,010 & 0,009 & 0.011 & 0,016 & 0,012 & 0,009 \\
\hline $\mathrm{Ni}$ & - & 0,003 & 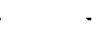 & - & 0.001 & 0,004 & \\
\hline $\mathrm{Mg}$ & 0,831 & 0,821 & 0,853 & 0,799 & 0.836 & 0,807 & 0.780 \\
\hline Ca & 0.783 & 0,768 & 0,811 & 0.790 & 0,769 & 0,809 & 0,820 \\
\hline $\mathbf{N a}$ & 0,034 & 0,035 & 0,024 & 0.023 & 0,0123 & 0,023 & 0.046 \\
\hline K & - & 0,001 & . & - & . & $=$ & $n, 001$ \\
\hline $\mathrm{MI}, \mathrm{M} 2$ & 2.033 & 2,027 & 2,014 & 2,013 & $2,04 !$ & 2,016 & 2,012 \\
\hline 0 & 6,000 & 6,000 & 6,0000 & 6,000 & 6,000 & 6,000 & 6,000 \\
\hline$w_{0}$ & $\$ 2,000$ & 40,000 & 42,000 & 41.000 & $59,0 \times 0$ & 42,000 & 43,000 \\
\hline En & 45.000 & 42,000 & 43,000 & 42.000 & $42,0 \times 01$ & 42,000 & 41,000 \\
\hline Fs & 13,000 & 18.000 & 15,000 & 17,000 & 19.000 & 16,000 & 16.000 \\
\hline $\mathrm{Fe}^{2+}+\mathrm{Mg}$ & 1,172 & 1.160 & 1.127 & 1,121 & 1.208 & 1,111 & 1.075 \\
\hline $11 \mathrm{gg}$ & 0,709 & 0.708 & 0.739 & 0,713 & 0,692 & 0,727 & 0,725 \\
\hline
\end{tabular}

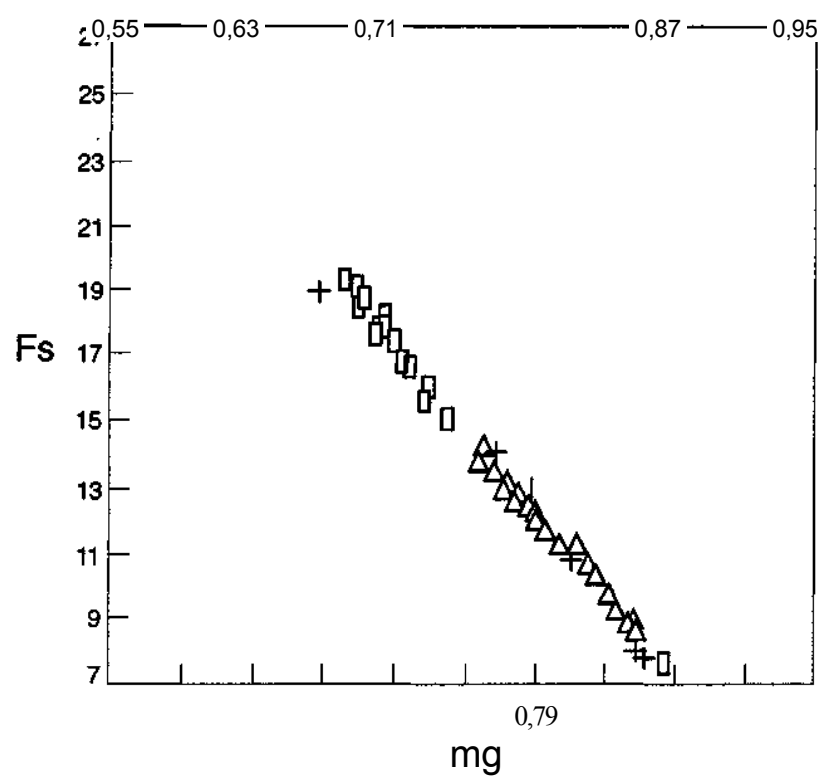

Figura 9 - Diagrama de correlação entre os conteúdos de $\boldsymbol{m g}$ $(\mathrm{Mg} / \mathrm{Mg}+\mathrm{Fe}$ ) e $\mathrm{Fs}$ (ferrossilita) dos clinopiroxênios da ASLS. Legenda: traquibasaltos $(\Delta)$, shoshonitos $(\square)>$ lamprófiros

(+).

Figure 9 - Correlation diagram of $\mathbf{m g}(\mathrm{Mg} / \mathrm{Mg}+\mathrm{Fe})$ values and Fs (ferrosilite) contents in clinopyroxenes from LSSA. Trachybasalts $(\Delta)$, shoshonites $(\square)$, lamprophyres (+).

Tabela 5c - Composição química e fórmula estrutural (6 oxigênios) do clinopiroxênio dos lamprófiros espessartíticos da ASLS. F= fenocristal; $b$ - borda de fenocristal; $c=$ centro de fenocristal; $M F=$ microfenocristal.

Table $5 \mathrm{c}$ - Chemical composition and structural formula (6 oxygens) of clinopyroxene from LSSA espessartitic lamprophyres. $\mathrm{F}=$ phenocryst; MF $=$ microphenocryst; $\mathrm{b}=$ phenocryst border; $\mathrm{c}=$ phenocryst core.

\begin{tabular}{|c|c|c|c|c|c|}
\hline \% peso & $\begin{array}{c}\text { LP230 } \\
\mathbf{F} \\
\end{array}$ & $\begin{array}{c}\text { L.P230 } \\
\mathrm{Fb}\end{array}$ & $\begin{array}{c}\text { LP226 } \\
\text { Fb }\end{array}$ & $\begin{array}{c}\text { LP226 } \\
\text { FC } \\
\end{array}$ & $\begin{array}{c}\text { LP230 } \\
\text { MF }\end{array}$ \\
\hline $\mathrm{SiO}_{2}$ & 51.31 & 53.24 & st.s5 & 52.66 & 51.00 \\
\hline $\mathrm{TiO}_{2}$ & 0.65 & 0.11 & 0.58 & 0.39 & 0.17 \\
\hline $\mathrm{Al}_{2} \mathrm{O}_{3}$ & 3.50 & 1.59 & 3.65 & 2.11 & 2.10 \\
\hline $\mathrm{Fe}_{2} \mathrm{O}_{3}$ & 0.00 & 0.00 & - & . & 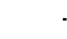 \\
\hline $\mathrm{Cr}_{2} \mathrm{O}_{3}$ & 0.03 & 0.50 & . & 0.08 & 1.34 \\
\hline FeO & 7.58 & 5.03 & 7.72 & 6.73 & 10.94 \\
\hline Mno & 0.28 & 0.23 & 0.23 & 0.20 & 0.49 \\
\hline $\mathrm{NiO}$ & 0.08 & - & 0.08 & 0.04 & 0.01 \\
\hline $\mathrm{MgO}$ & 15.32 & 15.60 & 14.89 & 16.13 & 12,24 \\
\hline $\mathrm{CaO}$ & 19.78 & 22.36 & 20.45 & 20.80 & 19.38 \\
\hline $\mathrm{Na}_{2} \mathrm{O}$ & 0.42 & 0.44 & 0.45 & 0.34 & 0.70 \\
\hline $\mathrm{K}_{2} \mathrm{O}$ & . & 0.05 & 0.01 & . & • \\
\hline Totil & 98.95 & 99.18 & 99.62 & 99.49 & 98.38 \\
\hline Si IV & 1.913 & 1.970 & 1.913 & 1.948 & 1.951 \\
\hline AlIV & 0.087 & 0.030 & 0.087 & 0.052 & 0.049 \\
\hline T sitc & 2.000 & 2.000 & 2.000 & 2.000 & 2.000 \\
\hline A) VI & 0.067 & 0.040 & 0.072 & 0.040 & 0.046 \\
\hline$T_{i}$ & 0.018 & 0.003 & 0.016 & 0.011 & 0.005 \\
\hline $\mathrm{Cr}$ & - & 0.015 & - & 0.002 & 0.040 \\
\hline $\mathrm{Fe}^{2+}$ & 0.237 & 0.156 & 0.240 & 0.208 & 0.350 \\
\hline $\mathrm{Mn}^{2+}$ & 0.009 & 0.007 & 0.007 & 0.006 & 0.016 \\
\hline $\mathrm{Ni}$ & 0.002 & - & 0.002 & 0.001 & \\
\hline $\mathrm{Mg}_{\mathrm{g}}$ & 0.852 & 0.861 & 0.824 & 0.889 & 0.698 \\
\hline $\mathrm{Ca}$ & 0.791 & 0.886 & 0.813 & 0.824 & 0.795 \\
\hline $\mathrm{Na}$ & 0.030 & 0.032 & 0.033 & 0.024 & 0.052 \\
\hline $\mathrm{K}$ & 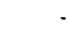 & 0.002 & - & . & - \\
\hline M1, M2 & 2.006 & 2.002 & 2.008 & 2.006 & 2.002 \\
\hline 0 & $6 .(N)$ & 6.000 & 6.00 & 6.00 & 6.00 \\
\hline Wo & 42.00 & 46.00 & 43.00 & 43.00 & 43.00 \\
\hline En & 45.00 & 45.00 & 44.00 & 46.00 & 37.00 \\
\hline Fs & 13.00 & 9.00 & 13.00 & 11.00 & 20.00 \\
\hline $\mathrm{Fe}^{2+}+\mathrm{Mg}$ & 1.088 & 1.016 & 1.064 & 1.097 & 1.048 \\
\hline $\mathrm{mg}$ & 0.783 & 0.847 & 0.775 & 0.810 & 0.666 \\
\hline
\end{tabular}


clinopiroxênios nas rochas menos diferenciadas, fato este que coincide com os resultados de Kushiro (1960), que demonstram um decréscimo de $\mathrm{A} 1^{\mathrm{IV}}$ na evolução de líquidos básicos. Barberi et al (1971) atribuem ao teor de $\mathrm{Al}_{2} \mathrm{O}_{3}$ dos piroxênios uma vinculação a pressão e temperatura de cristalização, bem como à natureza química do magma. Neste último caso, segundo estes autores, o fator determinante é a atividade da sílica que, quando reduzida, possibilita uma maior incorporação da molécula de $\mathrm{CaAl}_{2} \mathrm{SiO}_{6}$. No caso das rochas da ASLS, pode-se supor que os líquidos básicos e intermediários tiveram a atividade de $\mathrm{SiO}_{2}$ reduzida, como demonstrado pela estabilidade de olivinas nestas rochas, ao invés de ortopiroxênio.

Os teores de Mn correlacionam-se de forma positiva com os conteúdos de Fe refletindo o comportamento semelhante destes elementos. Os teores de $\mathrm{TiO} 2$ são geralmente inferiores a $1 \%$. Deer et al. (1980) sugerem que a variação do Ti nos clinopiroxênios pode estar vinculada à diferenciação magmática. No entanto, esses mesmos autores reconhecem que tanto pode ocorrer um aumento como um decréscimo de Ti no clinopiroxênio com a evolução dos magmas.

No caso de Lavras do Sul, a formação de ilmenita nas rochas básicas e titanomagnetita a partir das composições andesíticas pode ter influenciado na distribuição de $\mathrm{TiO}_{2}$ no clinopiroxênio.

Wass (1979) observou que o teor de $\mathrm{Ti}^{4+}$ aumenta com o decréscimo de $\mathrm{Cr}^{3+}$ nos clinopiroxênios, e que a presença deste último está vinculada aos teores presentes no líquido. Esta relação é observada nos clinopiroxênios da ASLS (Fig. 11).

\section{ANFIBÓLIOS DOS LAMPRÓFIROS ESPES-} SARJÍTICOS O anfibólio é a fase mineral dominante nos lamprófiros espessartíticos e não foi identificado nas rochas vulcânicas básicas e intermediárias. Os elementos considerados têm as seguintes posições no cálculo da fórmula estrutural utilizada:

$$
\begin{aligned}
& \mathrm{A}^{1+}=\mathrm{Na}, \mathrm{K} ; \\
& \mathrm{B}^{2+}=\mathrm{Ca}, \mathrm{Na}, \mathrm{Fe}^{2+}, \mathrm{Mn}_{\mathrm{Mg}} \\
& \mathrm{C}=\mathrm{Mg}, \mathrm{Fe}^{2+}, \mathrm{Mn}^{\mathrm{Vl}}, \mathrm{Cr}, \mathrm{Ti}^{\mathrm{F}} \mathrm{Fe}^{3+} ; \\
& \mathrm{T}=\mathrm{Si}, \mathrm{Al}^{\mathrm{IV}}
\end{aligned}
$$

O cálculo foi efetuado em base a 23 oxigênios, optando-se pelo procedimento que admite a soma do total de cátions igual a 13, com exceção de Na-K-Ca. Nesta opção, somente Ca e

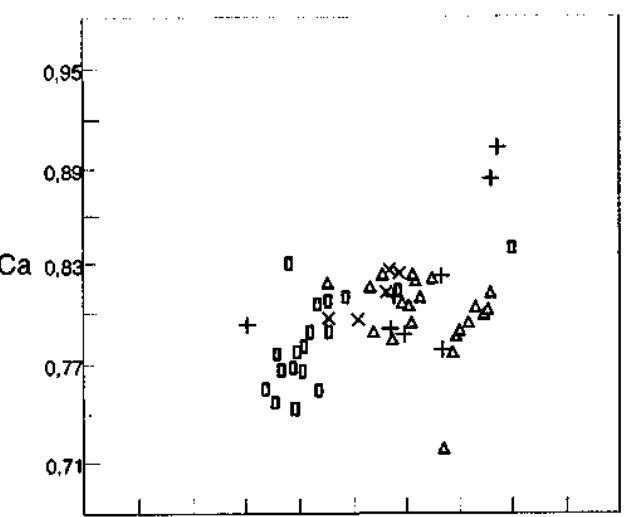

Na são permitidos na posição M4 e apenas Na e K ocupam o

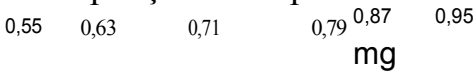

Figura 10 - Diagrama de correlação entre os conteúdos de $m g(\mathrm{Mg} / \mathrm{Mg}+\mathrm{Fe})$ e $\mathrm{Ca}^{2+}$ (fórmula estrutural) dos clinopiroxênios da ASLS. Legenda: traauibasaltos $(\Delta)$, shoshonitos( ), lamprófiros (+).

Figure 10 - Correlation diagram of $\mathbf{m g}(\mathrm{Mg} / \mathrm{Mg}+\mathrm{Fe})$ values and $\mathrm{Ca}^{2+}$ (structural formula) in clinopyroxenesfrom LSSA.Trachybasalts(A), shoshonites(), lamprophyres (+). sítio A. Este procedimento permite uma distribuição mais realista de $\mathrm{Na}$ entre as posições $\mathrm{A}$ e $\mathrm{B}$. Os dados obtidos enquadram os anfibólios estudados no grupo dos anfibólios cálcicos, que foram assim definidos a partir dos critérios de Leake et al. (1997) que define este grupo como monoclínico, $(\mathrm{Ca}+\mathrm{Na})_{\mathrm{B}} \geq 1$ e $\mathrm{N}_{\mathrm{aB}}<0,50$ e $\mathrm{C}_{\mathrm{aB}} \geq 1,50$. As análises selecionadas, bem como a fórmula estrutural dos anfibólios e classificação, são apresentadas na tabela 6 .

Nos lamprófiros espessartíticos domina a composição de magnesiohastingsita. Essa composição assemelha-se àquelas apresentadas por Rock (1984) como sendo típica de lamprófiros dessa natureza.

Outro fato destacável é a substituição $\mathrm{Si}-\mathrm{NaAl}^{\mathrm{IV}}$ (Fig. 12) no anfibólio dos espessartitos. Tal aspecto coincide com a observação de Giret et al. (1980), que colocam este tipo de substituição como característica de anfibólios cálcicos, gerados apartir de líquidos saturados em $\mathrm{SiO}_{2}$. A correlação entre $\mathrm{Fe}^{3+(\mathrm{c})}$ e Na ${ }^{(\mathrm{B})}$ sugere uma substituição do tipo riebequítica no anfibólio dessas rochas (Fig. 13). De acordo com Mitropoulos \& Tarney (1992), tal tipo de substituição reflete a natureza da fase fluida; no caso dos lamprófiros da ASLS, parece estar relacionada a variações na $\mathrm{fO}_{2}$. Observa-se também uma notável semelhança entre os anfibólios da ASLS e os descritos por Ewart (1982) como característicos das rochas vulcânicas orogênicas. $\mathrm{O}$ conjunto total dos dados ocupa o campo definido para rochas orogênicas (Fig. 14).

CONCLUSÕES A mineralogia essencial das rochas vulcânicas básicas e intermediárias da ASLS é representada por plagioclásio do tipo andesina-labradorita sódica. Esta é acompanhada por olivina $\left(\mathrm{Fo}_{67}\right)$ e augita, sendo a estabilização da olivina em líquidos intermediários relacionada ao conteúdo expressivo de álcalis, especialmente $\mathrm{K}_{2} \mathrm{O}$, o que ocasiona uma menor atividade da sílica, ampliando o campo de cristalização desta fase. A olivina apresenta maiores concentrações de ferro do que as observadas nas demais séries magmáticas e o clinopiroxênio caracteriza-se por um expressivo conteúdo da molécula de wollastonita. $\mathrm{O}$ fracionamento destes minerais em líquidos básicos shoshoníticos determina uma posição limite entre as séries cálcico-alcalina e toleítica nos diagramas que utilizem razões $\mathrm{Feo} / \mathrm{MgO}$, bem como sua natureza álcalicálcica. Tais aspectos de química mineral caracterizam uma identidade para a série shoshonítica. Destaca-se também uma coerência entre o quimismo de rocha total (natureza álcali-cálcica) e a química mineral da ASLS, o que permite sugerir a

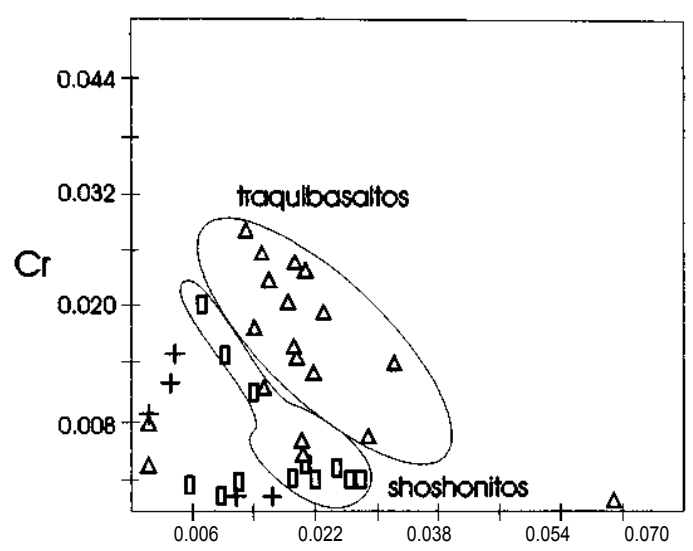

Figura 11 - Diagrama de correlação entre as proporções moleculares de Ti e Cr dos clinopiroxênios da ASLS. Legenda: traquibasaltos $(\Delta)$, shoshoni-tos( ), lamprófiros (+). Figure 11 - Correlation diagram of $\mathrm{Ti}$ and $\mathrm{Cr}$ (structural formula) in clinopyroxenes from LSSA. Trachybasalts( $\Delta)$, shoshonites( ), lamprophyres (+). 


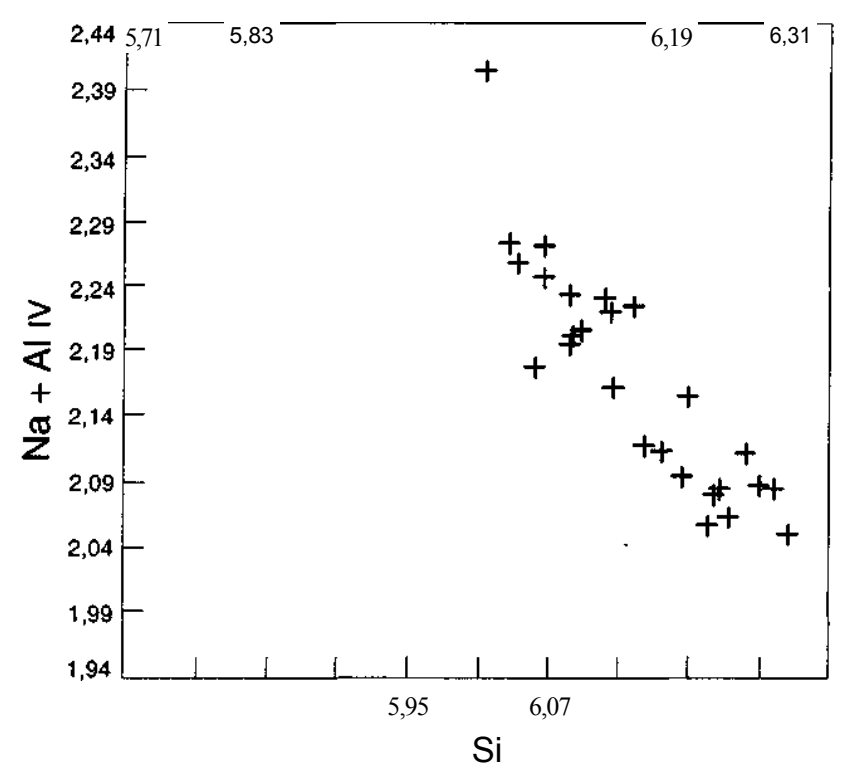

Figura 12 - Diagrama de correlação entre as proporções moleculares de Si e $\mathrm{Na}+\mathrm{Al}^{I V}$ do anfibólio das rochas espessartíticas da ASLS.

Figure 12 - Correlation diagram of $\mathrm{Si}$ and $\left(\mathrm{Na}+\mathrm{Al}^{\mathrm{VI}}\right)$ molecular proportions in amphibole from espessartitic rocks of LSSA.

Tabela 6 - Composição química e fórmula estrutural (23 oxigênios) magnesiohastingsita dos lamprófiros (LP) espessartíticos da ASLS. F=fenocristal; Fb = borda de fenocristal; $F_{c}=$ centro de um feno cristal; $M F=$ microfenocristal . Table 6 - Chemical composition and structural formula ( 23 oxygens) of magnesiohastingsite from LSSA espessartitic lamprophyres (LP). F= phenocryst, (b) border, ( c) core, $\mathrm{Mf}=$ microphenocryst.

\begin{tabular}{|c|c|c|c|c|c|c|c|}
\hline & $\begin{array}{c}\text { I. Prolp } \\
\text { F }\end{array}$ & $\begin{array}{c}\text { LPOIP } \\
F \mathbf{n}\end{array}$ & $\begin{array}{l}\text { I.P22, } \\
\text { Fh }\end{array}$ & $\begin{array}{c}\text { I.POIP } \\
F c\end{array}$ & $\begin{array}{c}\text { I.1.122 } \\
F c\end{array}$ & $\begin{array}{c}\text { I.POIP } \\
\text { MF }\end{array}$ & $\begin{array}{c}\text { LPENS } \\
\text { MFF }\end{array}$ \\
\hline Sink & 40,77 & 40,77 & 40,86 & 43,27 & $41,(14)$ & 40,63 & 41,45 \\
\hline$\pi D_{3}$ & 2.86 & 2,37 & 1,77 & 2.12 & 2,103 & 2,23 & $1, \forall 1$ \\
\hline $\mathrm{Al}_{2} \mathrm{O}_{3}$ & 12,68 & $12,7 \mathrm{R}$ & 13,39 & 11,22 & 12,91 & 12,80 & 12,34 \\
\hline FoO & $\$ 5.10$ & $15,4 \mathbf{3}$ & 10,24 & 13.24 & 16,18 & 16,22 & 16.37 \\
\hline MnO & 0,201 & 0,18 & 0,37 & 0,54 & 11.24 & $0, H$ & 01.23 \\
\hline Mgo & 10.98 & 11.23 & 11,02 & $13,+6$ & 11,02 & 10,62 & 11,23 \\
\hline $\mathrm{CaO}$ & $|10,7|$ & 10,65 & 11).,05 & 10.84 & 10.56 & 10.50 & {$[1,5]$} \\
\hline $\mathrm{Na}_{4} \mathrm{O}$ & 2,26 & 2,53 & 2,63 & 2,45 & 2,55 & $2,3 !$ & 2.32 \\
\hline $\mathrm{K}_{2} \mathrm{O}$ & 1.15 & 1,09 & 11.87 & 1,015 & 1.06 & 1,07 & 1,31 \\
\hline Toral & 96,77 & 97,01 & 97,24 & 98,22 & 97.54 & 96,39 & 97.67 \\
\hline $\mathrm{si}$ & 6.1991) & 0,000 & 6.010 & 6.276 & 6,0601 & 6)(109) & 6.120 \\
\hline Allv & 1.910 & 1,9411 & 1,990 & 1.730 & 1.9411 & J.91। & 1.880 \\
\hline Solna $T$ & 8,0001 & 8,00010 & צ., & $8,000)$ & $8,(100)$ & B. (H) & $8(x)$ \\
\hline Alv] & 0,320 & $(0,3(4)$ & 0,3411 & $(0,1 \%)$ & (0.310 & 0,350 & 0,2711 \\
\hline $\mathrm{Fe}^{3++}$ & 0,640 & 0,780 & 1,170 & $0,1,30$ & (1),800) & 0,820 & (1. 9 체 \\
\hline $\mathrm{T}$ & 0,320 & $(1,260)$ & 0,200 & $(1,230)$ & 0,230 & 0,250 & $0,2+1+1$ \\
\hline $\mathrm{Mg}$ & 2.440 & 2500 & 2,420 & 2,9111 & 2,430 & 2,370 & 2,470 \\
\hline $\mathrm{Fec}^{2+}$ & 1,240 & $1,\{40\}$ & 0.830 & 0.780 & 0.1100 & 1,260 & 1,10601) \\
\hline $\mathrm{Mn}$ & 0,030 & 0.120 & 11,450 & 0.070 & $0,03 n$ & 0,000 & $(0,030)$ \\
\hline Solma C & $s_{2}(x)=0$ & $5, \mathrm{HM} / \mathrm{r}$ & S.MNO & S,IKM & 5,0041 & 9,0000 & 5,000 \\
\hline $\mathbf{C a}$ & 1.710 & 1,6994 & 1,590 & 1,640 & 1.670 & 1,600 & 1,660 \\
\hline $\mathrm{Nu}_{\mathrm{i}}$ & 0,294 & $\{1,310$ & 0,410 & (1.320 & $0 ., 3311$ & 0,314 & (t. .340 \\
\hline Sund B & $2,0 \times 10$ & 2,000 & 2,000 & $2,0 \times 1)$ & 2,000 & 2,000 & 2.14k: \\
\hline$N_{a}$ & 0,377 & 10,420 & 0,340 & 0.370 & $(0,4+\infty)$ & 0,360 & (1.)3411 \\
\hline$k$ & 0,220 & 0,210 & 4,160 & 11,9911 & $0.2(x)$ & 00,200 & 0.230 \\
\hline Sothia A & 0,590 & 11,630 & 10,500 & 0.570 & (1),6(x) & 0,560 & 0.5710 \\
\hline 乏Ctions: & |5.59: & 15,640 & $15,5(5 \mathrm{ni})$ & 15,570 & 15,600 & $(15,5(x)$ & $15.5 \%$ \\
\hline $\mathrm{K}+\mathrm{Na}$ & 0,550 & 11,630 & 0,500 & 0,570 & 0,000 & 11,$560 ;$ & 0,570 \\
\hline
\end{tabular}

hipótese de cristalização fracionada como adequada para a evolução de líquidos shoshoníticos (Lima \& Nardi, 1998).

$\mathrm{O} \mathrm{Kd}$ mais elevado do $\mathrm{Ba}$ em plagioclásio parece estar relacionado ao expressivo conteúdo de $\mathrm{K}$ em líquidos básicos shoshoníticos. Este fato deve ocasionar um aumento do componente ortoclásio nesta fase com a consequente geração de sítios estruturais compatíveis com o Ba.

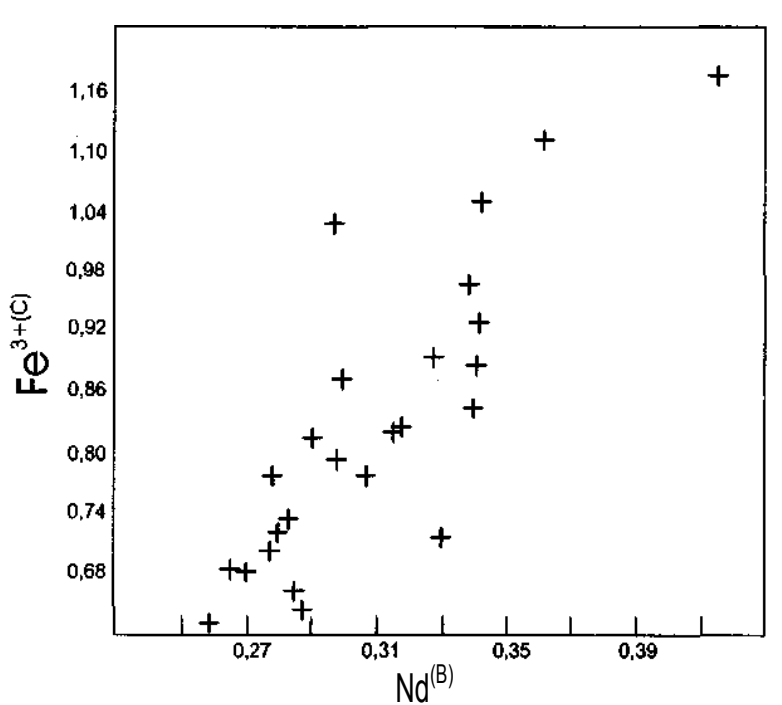

Figura 13 - Diagrama de correlação entre as proporções moleculares de $\mathrm{Fe}^{3+(c)}$ e $\mathrm{Na}^{(b)}$ (substituição riebequitica) do anfibólio das rochas espessartíticas da ASLS.

Figure 13 - Correlation diagram of $\mathrm{Fe}^{3+(\mathrm{C})} \mathrm{e} \mathrm{Na}{ }^{(B)}$ molecular proportions (riebeckite substitution) in amphibole of LSSA.

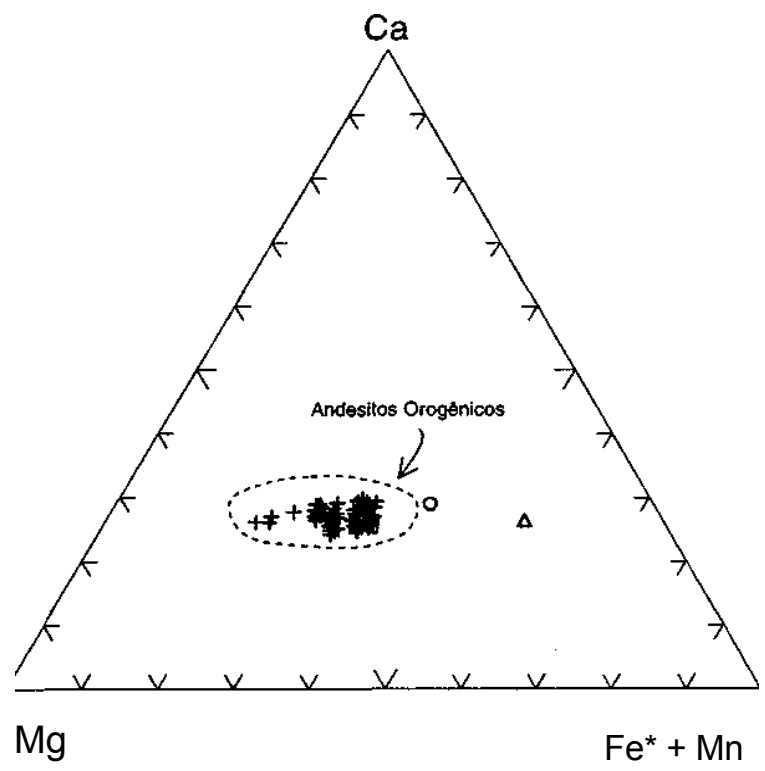

Figura 14 - Composição do anfibólio das rochas da ASLSprojetados em percentagem atómica de $\mathrm{Mg}, \mathrm{Fe} *+\mathrm{Mn}$ e Ca. O campo tracejado marca a composição dominante de anfibólios de rochas intermediárias, orogênicas, segundo Ewart (1982).

Figure 14 - Compositions of LSSA amphibole relative to the field of amphiboles from orogenic intermediate rocks according to Ewart (1982).

O plagioclásio original dos lamprófiros espessartíticos é possivelmente andesina sendo os tipos mais albíticos originados por transformações hidrotermais. A composição típica do anfibólio é magnesiohastingsita e o clinopiroxênio reliquiar possui um quimismo semelhante ao observado nas rochas vulcânicas básicas, embora enriquecido em componente diopsídio. Este último fato aliado à evidências geoquímicas (Lima e Nardi 1998) de rocha total permite sugerir que esse segmento da ASLS originou-se a partir de líquidos básicos shoshoníticos contaminados por assimilação de materiais crustais. 
Agradecimentos À Fundação de Amparo à Pesquisa do Rio Grande do Sul (FAPERGS) e ao Conselho Nacional de Desenvolvimento Científico e Tecnológico (CNPq), Centro de Estudos em Petrologia e Geoquímica- CPGq, pelo apoio A.M., Essene, E.J. 1988. A microcomputer program for storage and 73:446-448.

Allan, J.F.; Charmichael, I.S.E. 1984. Lamprophyric lavas in the Colima graben, SW México. Contrihutions to Mineralogy and Petrology, 88:203-216.

Barberi, F.; Bizouard, H.; Varet, J. 1971. Nature of the clinopyroxene and iron enrichment in alkalic and transitional basaltic magmas. Contributioiis to Mineralogy and Petrology, 33: 93-107.

Charmichael, I.S.E.; Turner, F.J. ; Verhoogen, J. 1974. Igneous Petrology. New York, McGraw-Hill Book. 739 p.

Deer, W.A, Howie, R.A.; Zussman, J. 1980. An introduction to the rock-forming minerais. London, Longman Group Limited. 528 p.

Deer, W.A.; Howie, R.A. ; Zussman, J. 1982. Orthosilicates. IA. London, Longman. 919p.

Dungan, M.A.; Rhodes, M.J. 1978. Residual glasses and melt inclusions in basalts from DSDP legs 45 and 46: Evidence for magma mixing. Contributions to Mineralogy and Petrology, 67: 417-431.

Ewart, A. 1982. The mineralogy and petrology of Tertiary-Recent orogenic volcanic rocks: with special reference to the andesite-basalt composicional range. In: Thorpe, R.S. ed. Andesites: Orogenic Andesites and related rocks. New York, John Willey; Sons. p. 25-95.

Gest, D.E.; McBirney, A.R. 1979. Genetic relations of shoshonitic and absarokitic magmas, Absaroka Montains, Wyoming. Journal of Volcanology and Geothermal Research, 6: 85-104.

Gill, J.B. 1981. Orogenic Andesites and Plate Tectonic. New York, Springer-Verlag. 390p.

Giret, A.; Bonin, B.; Leger, J.M. 1980. Amphibole composition trends in ones saturated and undersaturated alkaline plutonic ring-complexes. The Canadian Mineralogist, 18: 481-495.

Girod, M. 1978. Lês séries magmatiques. In: Girod, M. ed. Lês raches volcaniques - Pétrologie et cadre structural. Doin, Paris, p. 7-30.

Green, T. H. 1982. Anatexis of mafic crust and high pressure cristallization of andesite. In: Thorpe, R.S. ed. Andesites: Orogenic Andesites and Related Rocks. New York, John Willey; Sons. p. 465-487.

Haase, C.S.; Chadam, J.; Feinn, D.; Ortoleva, P. 1980. Oscillatory zoning in plagioclase feldspar. Science, 209: 272-274.

Halsor, S. 1989. Large inclusions in plagioclase phenocrysts and their bearing on the origin of mixed lavas Tolimán Volcano, Guatemala. Bulletim Volcanology, 51:271-280.

Helz, R.T. 1973. Phase relations of basalts in their melting range at $\mathrm{PH}_{2} \mathrm{O}=5 \mathrm{~Kb}$ as a function of oxygen fugacity. Journal of Petrology, 14: 249-302.

Henderson, P. 1982. Inorganic Geochemistry. New York, Pergamon Press. 353p.

Klein, F.W.; Koynagi, R.Y.; Nakata, J.S. AND Tanigawa, W.R. 1987. The seismicity of Kilauea's magma system. Unated States Geological Survey Professional Paper, 1350(2): 1019-1185.

Kontak, D.J.; Clark, A.LH.; Farrar, E.; Pearce, T.H.; Strong, D.F.; Baadsgaard, H. 1986. Petrogenesis of a Neogene Shoshonite Suite, Cerro Moromoroni, Puno, Southeas Peru. The Canadian Mineralogist, 24:117-135.

Kuo, L.C. \& Kirkpatrick, RJ. 1982. Pre-eruptive history of phyric basalts from DSDP Legs 45 and 46: Evidence from morphology and zoning patterns in plagioclase. Contributions to Mineralogy and Petrology, 79:13-27.

Kushiro, I. \& Yoder, H.S. Jr. 1966. Anorthite-forsterite and anorthite-enstatite reactions and their bearing on the basalt-eclogite transformation. Journal of Petrology, 7:337-362.

Kushiro, I. 1960. Si-Al relation in clinopyroxenes from igneous rock. American Journal of Science 258(8):548-554.

Kushiro, I. 1975. On the nature of silicate melts and its significance in magma génesis: Regularities in the shift of the liquidus boundaries involving olivine, pyroxene, and sílica minerais. American Journal of Science, 275:411-431.

Lê Bas, M.J. 1962. The role of aluminum in igneous clinopyroxenes with relation to their parentage. American Journal of Science, 260:267-288.

Leake, B.E.; Woolley, A.R.; Arps, C.E.S.; Birch, W.D.; Gilbert, M.C.; Grice, J.D.; Hawthorne, F.C.; Kato, A; Kisch, H.J.; Krivovichev, V.G; Linthout, K. Laird, J.; Mandarino, J.A.; Maresch, W.; Nickel, E.H.; Rock, N.M.S.; Shumacher, J.C.; Smith, D.C.; Stephenson, N.C.N.; Ungaretti, L; Whittaker, E.J.W.; Youzhui, G. 1997. Nomenclature of amphiboles: report of the Subcommittee on Amphiboles of the International Mineralogical Association. Commission on new minerais and mineral names. The Canadian Mineralogist. 35(1):219-246.

Lima, E.F. 1995. Petrologia das Rochas Vulcânicas e Hipabissais da Associação Shoshonítica de Lavras do Sul-ASLS, RS. Instituto de Geociências, Universidade Federal do Rio Grande do Sul, Porto Alegre, Tese de Doutorado, $338 \mathrm{p}$.

Lima, E.F.; Nardi, L.V.S. 1991. Os lamprófiros espessartíticos da Associação Shoshonítica de Lavras do Sul, RS. Geochimica Brasilienses, 5 financeiro e científico, a dois revisores anónimos da RBG e aos bolsistas de Iniciação Científica Daniel Fernandes Matos (FAPERGS) e Eduardo Rechziegel de Sousa (CNPq) pelo esforço na realização do presente trabalho.

\section{Referências}

Lima, E.F. \& Nardi, L.V.N. 1998. The Lavras do Sul Shoshonitic Association: implications for the origin and evolution of shoshonitic magmatism in southernmost Brazil. Journal South American Earth Sciences, (no prelo).

Lofgren, G. 1974. An experimental study of plagioclase morfology: isothermal cristalization. American Journal of Science, 273: 243-273.

Mackenzie, D.E. 1976. Nature and origin of Late Cenozoic volcanoes in western Papua New Guinea, Contributions to Mineralogy and Petrology, 35:50-62.

Meen, J.K. 1987. Formation of shoshonites from calcalkaline basalt magmas: geochemical and experimental contrains from the type locality. Contributions to Mineralogy and Petrology, 97:333-351.

Mitropoulos, P.; Turney, J. 1992. Significance of mineral composition variations in the Aegean Island Are. Journal of Volcanology and Geothermal Research, 51: 283-303.

Morimoto, N.C. 1988. Nomenclature of pyroxenes. The American Mineralogist, 73:1123-1133.

Nardi, L. V. S. 1984. Geochemistry and Petrology ofthe Lavras Granite Complex, $R S$, Brasil. Universidade de Londres, Londres, Tese de Doutorado. $268 \mathrm{p}$. (inédito).

Nardi, L.V.S.; Lima, E.F. 1985. A Associação Shoshonítica de Lavras do Sul, RS. Revista Brasileira de Geologia, 15(2): 139-146.

Nelson, S.T.; Montana, A. 1992. Sieve-textured plagioclase in volcanic rocks produced by rapid descompression. The American Mineralogist, 77:1242-1249.

Nemec, D. 1966. Plagioclase albitization in the lamprophyric and lamproid dykes at eastern border of the Bohemian massif. Beitrage zur Mineralogie und Petrographie, 12:340-353.

Pe-Piper, G. 1984. Zoned pyroxenes from shoshonite lavas of Lesbos, Greece: inferences concerning shoshonite petrogenesis. Journal of Petrology, 25:453-472.

Perring, C.S.; Rock, N.M.S.; Golding, S.D.; Roberts, D.E. 1989. Criteria for the recognition of metamorphosed or altered lamprophyres: a case study from Archean of Kambalda, Western Austrália. Precambriam Research, 43:215-237.

Protska, H.J. 1973. Hybrid Origin ofthe Absarokite-Shoshonite-Banakite Series, Absaroka Volvanic Field, Wyoming. Geological Society of American Bulletim, 84:697-702.

Remus, MV.D; McNaughton, N.J; Hartmann, L.A.; Fletcher, LR. 1997. Zircon SHIRIMPdating and Nd isotope dataof granitoids ofthe São Gabriel Block, southern Brazil: evidence for an Archean/Paleoproterozoic basement. In: ISGAM/ II International Symposium on Granites and Associated Mineralization, Salvador, Brasil, Extended Abstracts, 271-272.

Rock, N.M.S. 1984. The nature and origin of calc-alkaline lamprophyres: minettes, vogesites, kersantites and espessartites. Transactions of the Royal Society Edimburg, 74:193-227.

Rock, N.M.S. 1991. Lamprophyres. Glasgow, Blackie. 285p.

Simkin, T.; Smith, J.V. 1970. Minor-element distribution in olivine. Journal of Geology, 78:304-325.

Smith, J.V. 1974. Feldspar mineralogy. New York, Springer-Verlag. 1: 627p.

Spera, F.J. 1980. Aspects of magma transport. In: R.B. HARGRAVES. ed. Physics ofmagmatic processes. New Jersey, Princeton University Press. p. 265-323.

Stormer, J.C. 1972. Mineralogy and petrology of Raton-Clayton volcanic field, northeastern New México. Geological Society of American Bulletim, 83:3299-3322.

Streckeisen, A. 1979. Classification and nomenclature of volcanic rocks, lamprophyres, carbonatites and melilitic rocks. Geologiste Rundschau, 69:194-207.

Tsuchiyama, A.; Takahashi, E 1983. Melting kinetics of a plagioclase feldspar. Contributions to Mineralogy and Petrology, 84:345-354.

Tsuchiyama, A. 1985. Dissolution kinetics of plagioclase in the melt system diopside-albite-anorthite, an origin of dusty plagioclase in andesites. Contributions to Mineralogy and Petrology, 89:1-16.

Vance, J.A. 1969. On synneusis. Contributions to Mineralogv and Petrology, 57:187-213.

Villari, L.; Nathan, S. 1978. Petrology of Filicudi Aeolian Archipelago. Bulletin of Volcanology, 41:81-95.

Wass, S. Y. 1979. Multiple origins of clinopyroxenes in alkali basaltic rocks. Lithos, 12:115-132.

Watkeys, M.K.; Armstrong, R.A. 1985. The importance of being alkaline deformed late Archaean lampropyric dykes, Central zone, Limpopo Belt Transactions Geological Society of South Africa, 88:195-206.

Manuscrito A-946

Recebido em 25 de outubro de 1997 Revisão dos autores em 15 de maio de 1998 Revisão aceita em 18 de maio de 1998 